\title{
CONODONTOS Y EPISODIOS CARBONATADOS EN EL SILÚRICO DE LA CADENA HERCÍNICA MERIDIONAL Y EL DOMINIO SAHARIANO
}

\author{
Susana GARCÍA-LÓPEZ', Rosario RODRÍGUEZ-CAÑERO², Javier \\ SANZ-LÓPEZ ${ }^{3}$, Graciela SARMIENTO ${ }^{4}$ y José Ignacio VALENZUELA- \\ RÍOS \\ 'Dpto. de Geología. Universidad de Oviedo. cl Arias de Velasco s/n. 33005 Oviedo. \\ 2 Dpto. de Geología y Ecología. Universidad de Málaga. 29(07। Málaga. \\ ${ }^{3}$ Fac. de CC. de la Educación. Universidad de la Coruña. 15011 A Coruña. \\ ${ }^{4}$ Dpto. de Paleontología. Universidad Complutense e Instituto de Geología Económica (CSIC-UCM). Facultad de CC. Geoló- \\ gicals. 28040 Madrid. \\ 5 Dpto. de Geología, Universidad de Valencia. cl Dr. Moliner 50. 46100 Burjasot (Valencia).
}

García-López, S., Rodríguez-Cañero, R., Sanz-López, J., Sarmiento, G. y Valenzuela-Ríos, J.I. 1996. Conodontos y episodios carbonatados en el Silúrico de la Cadena Hercinica meridional y del Dominio Sahariano. [Conodonts and carbonatic episodes in the Silurian System from the Hercinic Chain and the Saharian Domain]. Revista Española de Paleontología. N" Extraordinario, 33-57. ISSN 0213-6937.

\begin{abstract}
The taxonomic review of published and unpublished data concerning silurian conodonts from a large region that extends from Ardennes to western and central Sahara has enabled the identification of 63 specific and subspecific taxa; these taxa have been placed in a workable biozonation. The analysis of the fossil and lithological features of forty synthetic sections shows several faunal associations and their relation to the conditions of sedimentation. The Silurian System, in the studied domain, shows two main lithofacies, consisting of, pelites which progressively and heterochronously change to (1) coarse siliciclastic lithofacies, or (2) to cephalopod limestones attributed to deposits of distal ramp ("mediterranean facies"), or to bioclastic limestones deposited in marginal areas. Combining the information provided by conodonts and graptolites, a preliminary subdivision in four carbonate episodes is established for the Silurian rocks of the studied region; these episodes are chronologically arranged by using the succession of conodont zones. The oldest episode took place during the Llandovery, close to the Rhuddanian-Aeronian boundary, and is of local magnitude; the second episode began during the upper Llandovery -lower Wenlock: the third one happened during the uppermost Wenlock-Ludlow and the youngest during the Pridoli. The last two episodes correspond to a common sedimentation characterized by condensed carbonate intervals that in areas of greater clastic inflow are represented by distinct deepening horizons.
\end{abstract}

Keywords: Synthesis, Silurian, conodonts, biostratigraphy, carbonate episodes, southern Europe, northern Africa.

\section{RESUMEN}

Se han reunido y evaluado los datos (publicados e inéditos) sobre los conodontos silúricos en una región que se extiende desde las Ardenas hasta el Sahara occidental y central. Su revisión taxonómica ha permitido la identificación de 63 especies y subespecies, que han sido referidas a una biozonación útil. El análisis de los aspectos lito y bioestratigráficos de cuarenta secciones sintéticas de este ámbito pone en evidencia asociaciones de faunas características y su relación con la dinámica sedimentaria. El Sistema Silúrico, en la región investigada, presenta dos lifofacies mayores consistentes en, pelitas que gradan de manera heterócrona a (1) facies siliciclásticas groseras, o bien a (2) calizas de cefalópodos de rampa distal ("facies mediterránea") o a calizas bioclásticas en áreas marginales. Los datos proporcionados por los conodontos en los materiales carbonatados, contrastados con la información ofrecida por graptolitos, han permitido reconocer, con carácter preliminar, la existencia de cuatro episodios carbonatados, cuya edad está indicada por las Zonas de conodontos. El primer episodio se registra en el Llandovery, próximo al tránsito Rhuddaniense-Aeroniense y tiene un carácter local, el segundo se inicia en el Llandovery superior-Wenlock inferior, el tercero se instala desde el Wenlock más alto-Ludlow y el cuarto en el Prídoli, correspondiendo los dos últimos a la generalización de los intervalos condensados carbonatados y que en las áreas de mayor influjo clástico están representados por determinados horizontes de profundización.

Palabras clave: Síntesis, Silúrico, conodontos, bioestratigrafía, episodios carbonatados, Europa meridional, Africa septentrional.

\section{INTRODUCCIÓN}

La glaciación finiordovícica determinó cambios globales en las poblaciones de conodontos, y las faunas con alta diversidad y provincialismo fueron reemplazadas por asociaciones generalmente cosmopolitas y poco diversificadas cuyo desarrollo, en parte, estuvo condicionado por ambientes escasamente favorables y fluctuantes. El mayor porcentaje de 
la información disponible en síntesis acerca de los conodontos del Silúrico, procede de áreas como la norteamericana, báltica y siberiana, situadas en paleolatitudes bajas (Bergström, 1990); mientras que las referencias concernientes a áreas emplazadas en paleolatitudes altas son muy escasas, en parte debido a la ausencia generalizada de rocas carbonatadas, y por tanto su conocimiento es aún muy incipiente. En los últimos años hemos intentado soslayar este vacío de información con la realización de nuevas investigaciones (en gran parte inéditas) y la revisión preliminar de datos poco conocidos (Sarmiento y García-López, 1993; García-López et al. 1994).

Es por ello que en este trabajo se ha pretendido reunir toda la información disponible acerca de los conodontos de una región geográfica extensa, cuyos límites septentrional y meridional coinciden con las Ardenas y el Sahara occidental y central respectivamente. Los sectores en ella analizados como el Macizo Armoricano y NO del Macizo Central, Montaña Negra, Macizo de Mouthoumet, Pirineos, Cadenas Costeras Catalanas, Macizo Hespérico, Cerdeña, Maláguides, Gomárides, Meseta Marroquí, Anti-Atlas, Cadena de Ougarta, Sahara Argelino y Cuenca de Tindouf (Fig. 1), a excepción de las Ardenas, ocupaban una posición latitudinal elevada durante el Silúrico inferior, con una tendencia a desplazarse a latitudes menores en el transcurso de este Período debido al acercamiento paulatino de Gondwana hacia Báltica (Scotese y Mckerrow, 1990).

Para establecer las correlaciones bioestratigráficas y evaluar la diversidad de las asociaciones, estas se han actualizado aplicando criterios de taxonomía multielemental a todas las referencias taxonómicas previas, excepto en el caso de algunos elementos coniformes, de los que no se poseen datos suficientes (Anexo 1). Así, se han reconocido en el ámbito investigado 63 especies y subespecies de conodontos (Anexo 2) y todas ellas se han integrado en una base de datos (Tabs. 1-5). De los 27 géneros de conodontos reconocidos en el Silúrico (Aldridge, 1988), 19 de ellos están representados en la región, destacando por su abundancia y diversidad específica el grupo polifilético atribuido al género Ozarkodina.

El esquema bioestratigráfico que hemos adoptado es el propuesto en 1993 por la Subcomisión Internacional de Estratigrafía del Silúrico (ICS-IUGS), basado en Aldridge y Schönlaub (1989). Este esquema, que desarrolla el establecido por Walliser (1964), plantea ciertas imprecisiones relativas a la definición de los límites entre algunas biozonas. La variación en el concepto específico de algunas formas, junto a la distinta naturaleza de sus biozonas dificulta en muchos casos el establecimiento de correlaciones precisas (Sarmiento y García-López, 1993; García-López et al., 1994); más aún, incluso la correspondencia entre las biozonas de conodontos con respecto a las zonas estándar de graptolitos continúa siendo muy discutible. El esquema bioestratigráfico actual también resulta problemático cuando se aplica a secuencias pelágicas, o bien cuando se consideran asociaciones de conodontos de latitudes elevadas. Por todo ello hemos creído necesario introducir en este trabajo algunas modificaciones de carácter provisional (Fig. 2).

Así, para referir los conodontos del Llandovery de la Zona Cantábrica, Pirineos y Macizo de Mouthoumet, se han utilizado las Zonas de Aspelundia petila y A. fluegeli (Armstrong, 1990). Nuestra Zona de Ozarkodina sagitta agrupa las

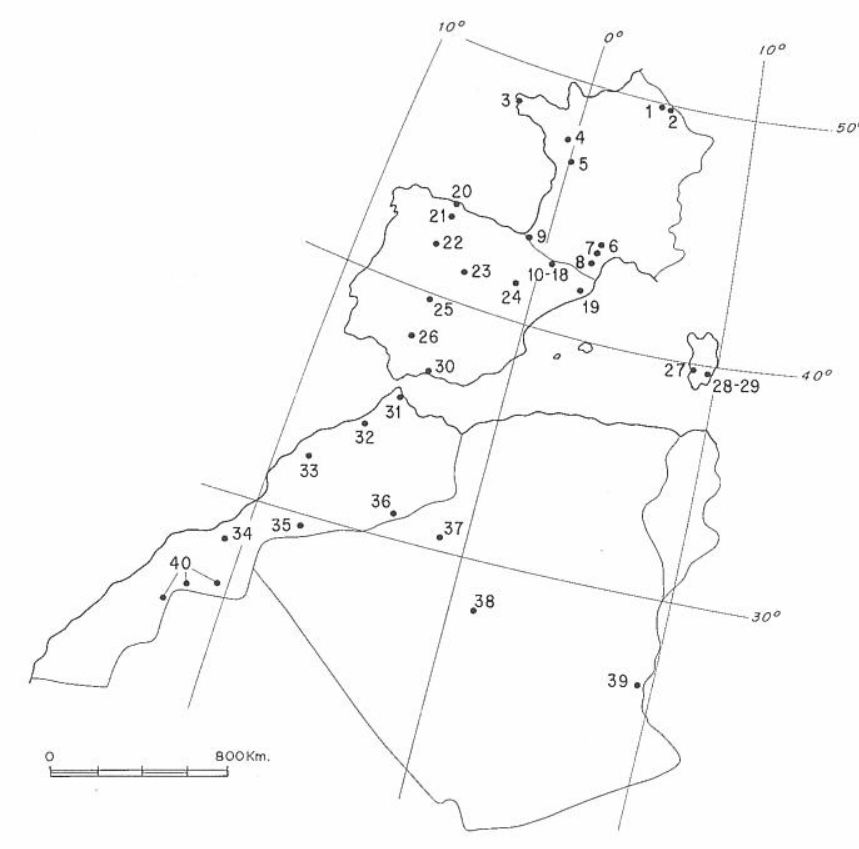

Figura 1. Localidades con conodontos del Silúrico y Devónico basal. N. de Francia y Ardenas: 1. Lievin, Artois, 2. Naux. Macizo Armoricano: 3. Península de Crozón, 4. Área de Angers. NO del Macizo Central: 5. Área de Limousin. SO del Macizo Central: Montaña Negra: 6. Septentrional, 7. Meridional. Macizo de Mouthoumet: 8. Pirineos, 9. Macizos vascos. Pirineos occidentales: 10. Valle de Tena; Pirineos centrales: 11. Sierra Negra, 12. Marimanya, 13. Llavorsí y Tor, 14. Les Nogueres; Pirineos orientales: 15 . Segre, 16. Collada de Toses y S. de Canigó, 17. Villefranche, 18. Aspres. Cadenas Costeras Catalanas, (CCC), 19. Macizo Hespérico: Zona Cantábrica: 20. Viodo, 21. Getino; Zona Centroibérica: 22- O de Zamora, 23- Guadarrama oriental, 25-Guadarranque; Cordillera Ibérica: 24- Bádenas; Zona de Ossa Morena: 26- Sinclinal del Valle. Cerdeña: SO: 27- Donigala y Fluminimaggiore; SE: 28- Pala Manna, 29-Silius; Cordilleras Béticas: 30- Maláguides (M). Cordillera de Rif: Gomárides: 31- Tetuán. Meseta Marroquí: 32- Área de Rabat-Tiflet, 33- Khemis n'Ga. Anti-Atlas: 34- Aïn Oui n'Delouine, 35- 1'Iriqui, 36- Taouz. Cadena de Ougarta: 37- Sahara Central: 38- Foum Hassi Taïbine, 39- FortTarat. Sahara occidental: 40- Cuenca de Tindouf.

actuales Zonas de $O$. sagitta sagitta y $O$. s. rhenana, debido a que los taxones nominales de las mismas son difíciles de evaluar en las referencias de trabajos previos cuando no vienen acompañadas de descripción o ilustración. Ancoradella ploeckensis (taxón que define la Zona homónima) sólo se ha identificado en dos de los cuarenta sectores analizados (SO y SE de Cerdeña), mientras que la Zona de Kockelella variabilis (Barrick y Klapper, 1976) se reconoce en un gran número de sucesiones, por lo que su aplicación en el esquema bioestratigráfico del ámbito investigado resulta más adecuada que la anterior. El límite inferior de la Zona de K. variabilis queda definido por la aparición del taxón nominal, en un nivel próximo a la base de la Zona de Neodiversograptus nilssoni de graptolitos (base del Ludlow) y el superior coincide con la primera aparición de Polygnathoides siluricus. Conforme a estas modificaciones, las zonas de conodontos 


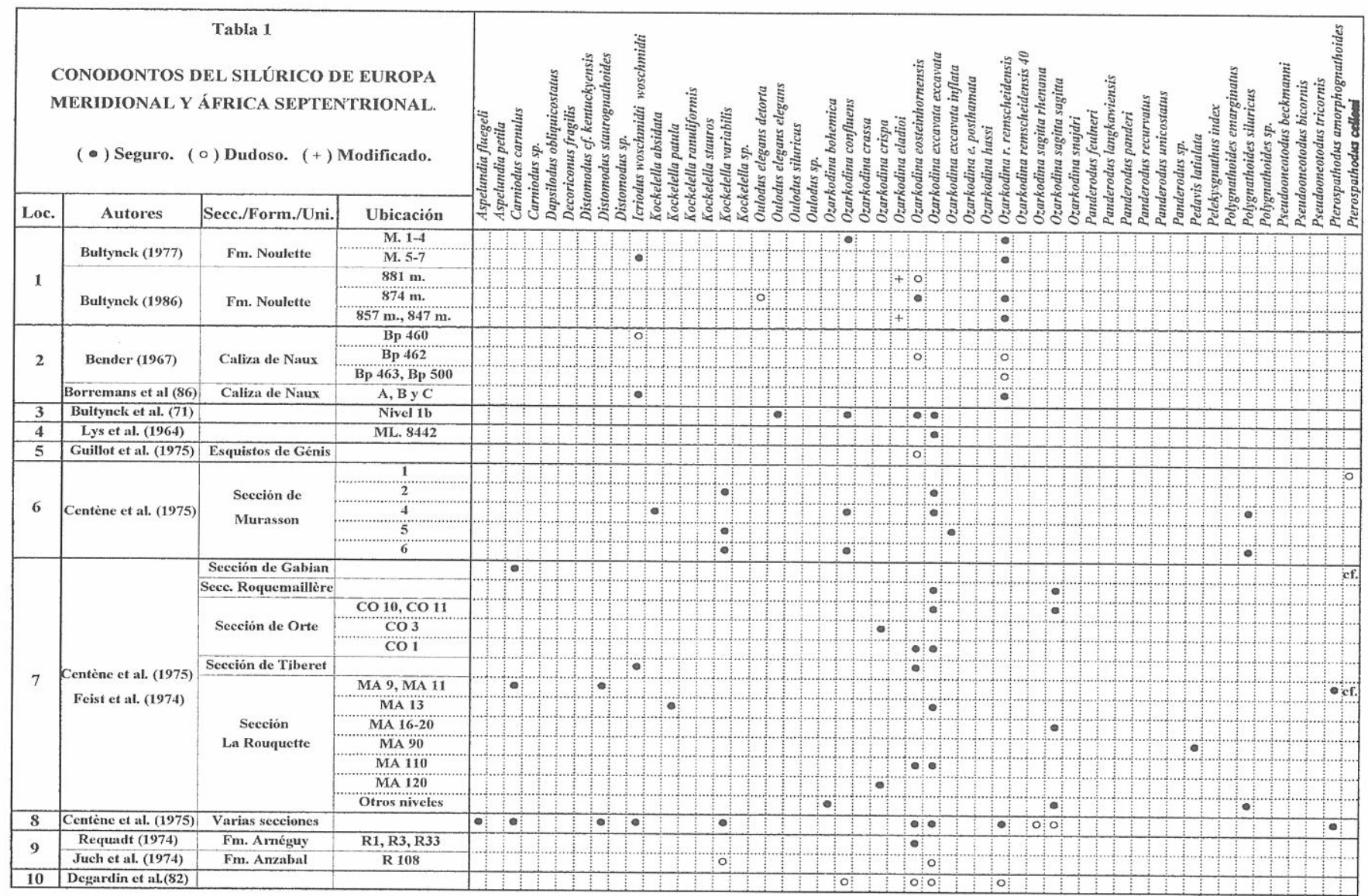

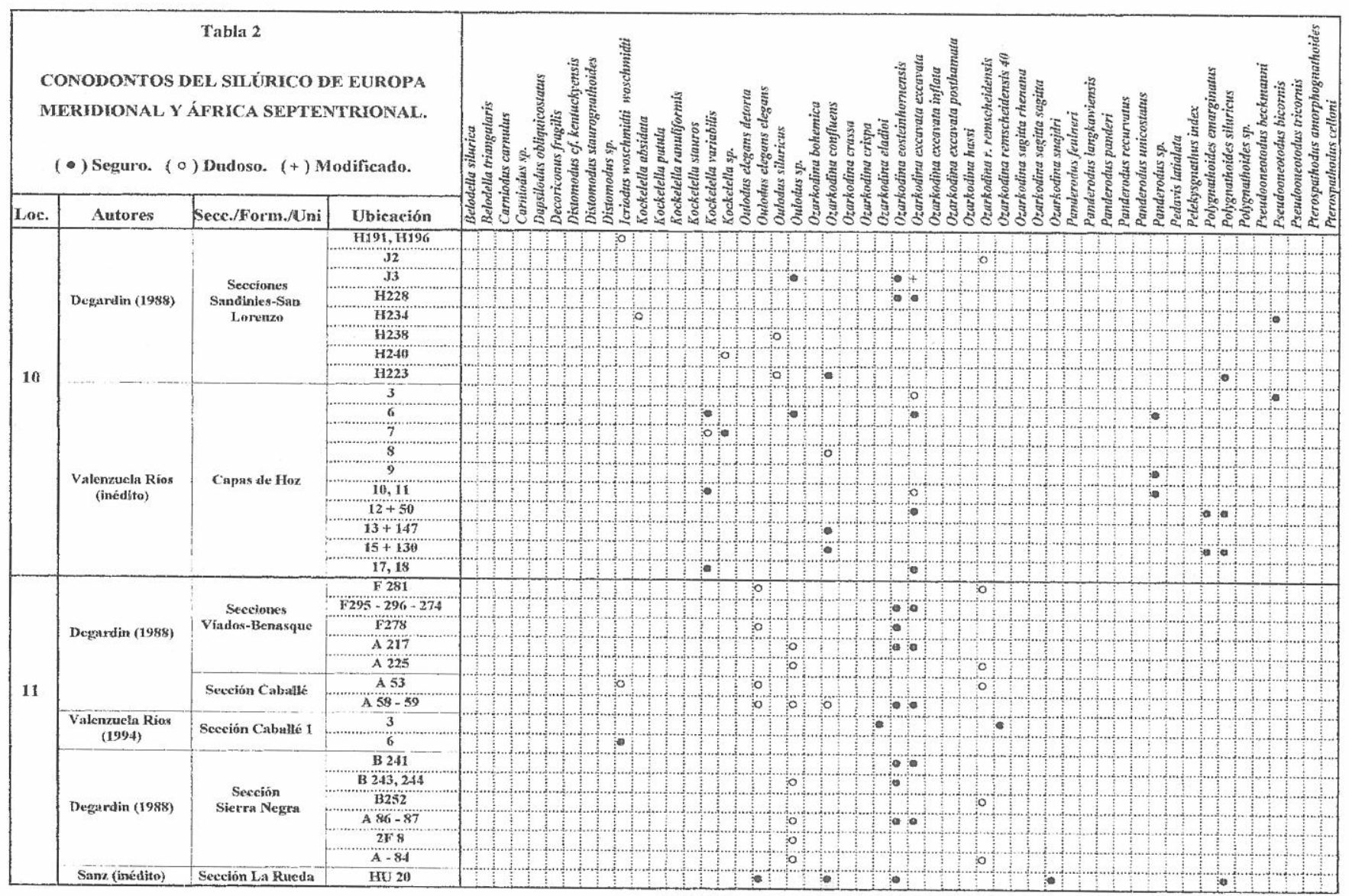




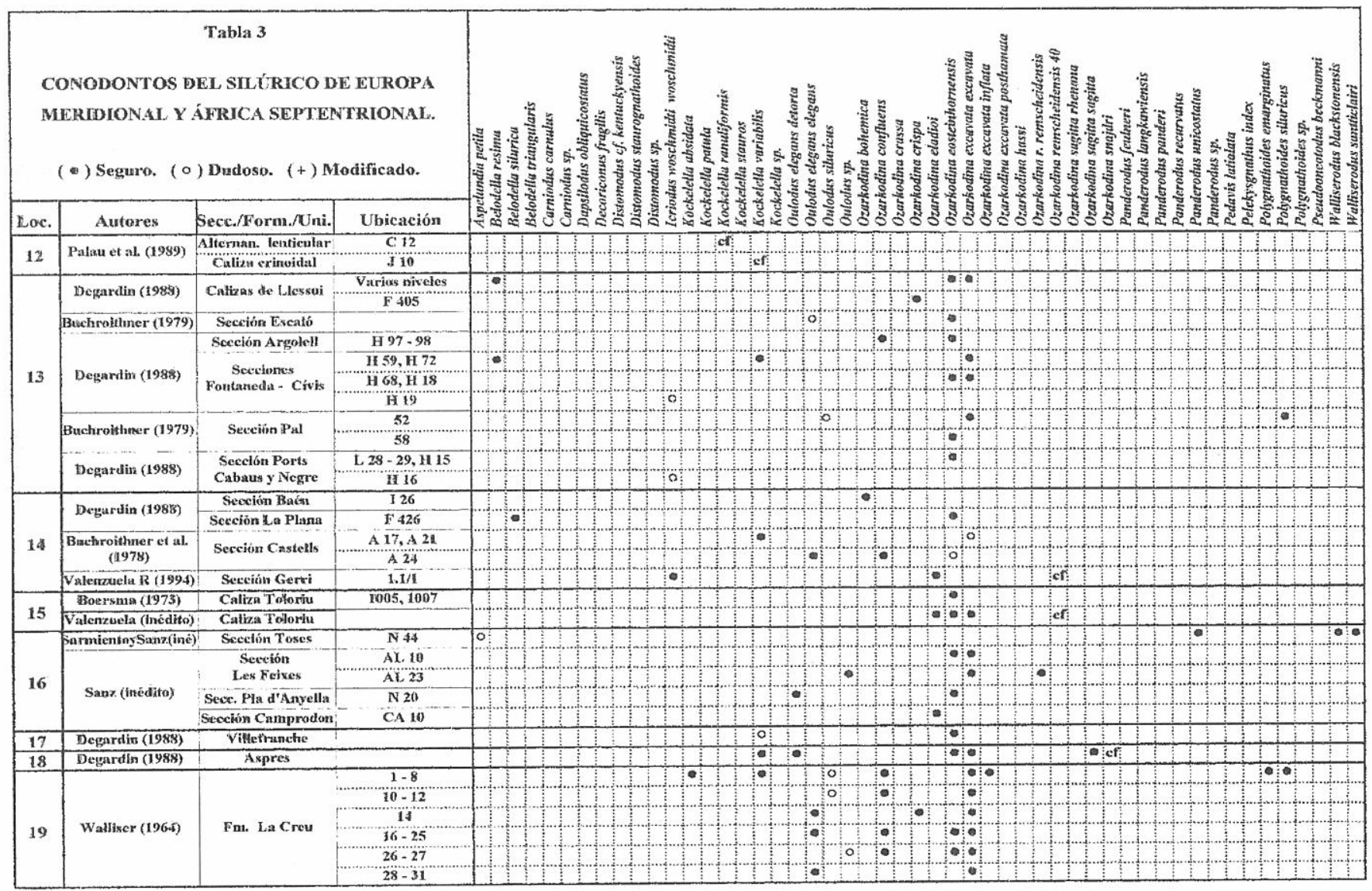

\begin{tabular}{|c|c|c|c|c|c|c|c|c|c|c|c|c|c|c|c|c|c|c|c|c|c|c|c|c|c|}
\hline \multirow{2}{*}{\multicolumn{4}{|c|}{$\begin{array}{c}\text { Tabla } 4 \\
\text { CONODONTOS DEL SILÚRICO DE EUROPA } \\
\text { MERIDIONAL Y AFRICA SEPTENTRIONAL. } \\
\text { (•) Seguro. ( ( ) Dudoso. }(+ \text { ) Modificado. }\end{array}$}} & \multirow{3}{*}{\multicolumn{5}{|c|}{ 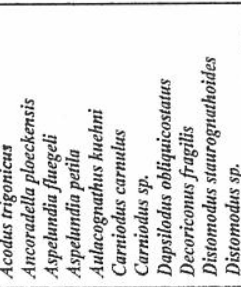 }} & \multirow{3}{*}{\multicolumn{5}{|c|}{ 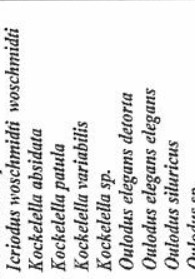 }} & \multirow{3}{*}{\multicolumn{4}{|c|}{ 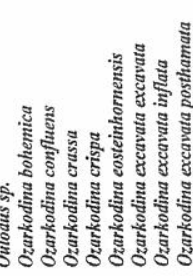 }} & \multirow{3}{*}{\multicolumn{3}{|c|}{ 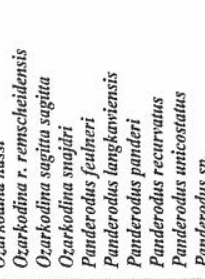 }} & \multirow{3}{*}{\multicolumn{3}{|c|}{ 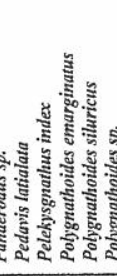 }} & \multirow{3}{*}{ 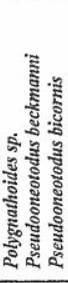 } & \multirow{3}{*}{ 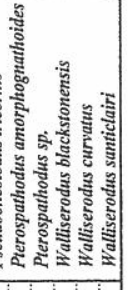 } \\
\hline & & & & & & & & & & & & & & & & & & & & & & & & & \\
\hline Loc. & \begin{tabular}{|l|} 
Autores \\
\end{tabular} & Secc./Form./Uni. & Ubicación & & & & & & & & & & & & & & & & & & & & & & \\
\hline \multirow{5}{*}{19} & Aldridge et al. (1985) & Fm. La Creu & & & & & & & & & & & & & & & & & & & & & & & \\
\hline & \multirow{3}{*}{ Sanz (inédito) } & \multirow{3}{*}{$\begin{array}{l}\text { Seccion } \\
\text { Les Gavarres }\end{array}$} & 1.2 & & & & & & & & & & & & & & & & & & & & & & \\
\hline & & & 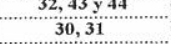 & & & & & & & & & & & & & & & & & & & & & 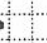 & \\
\hline & & & 269.28 & & & & & & & & & & & & & & & & & & & & & & \\
\hline & Sanzz, en & & Mi 28, & & & & & & & 6 & $\theta_{3}$ & & & & - & & -1. & & & & & & & 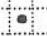 & \\
\hline \multirow{3}{*}{20} & \multirow{3}{*}{$\begin{array}{c}\text { Sarmiento et al. } \\
(1994)\end{array}$} & $\begin{array}{l}\text { Unidad Figuerola } \\
\text { Fm. Castro }\end{array}$ & $\begin{array}{l}\text { Mi } 29 \\
\text { in }\end{array}$ & & & & & & & 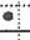 & $\bullet$ & & & & & & & & & & & & & : & \\
\hline & & $\begin{array}{l}\text { Fr. Castro } \\
\text { Michoro Yiodo }\end{array}$ & & & & & & & & & & & & & & & & & & & & & & & \\
\hline & & Miembro Viodo & Calizans superiores & & & & & & & & & & & & & & & & & & & & & & \\
\hline \multirow{3}{*}{22} & \multirow{3}{*}{ Quiroga $(1980,1982)$} & \begin{tabular}{|} 
"Capas de Getino" \\
Fm. San Vicente
\end{tabular} & $\begin{array}{c}\text { Dolomias } \\
\text { Base } \\
\end{array}$ & & & & & & & & & & & & - & 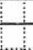 & 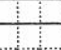 & & - & & & & & & \\
\hline & & \multirow{2}{*}{ Fm. Muga } & \multirow{2}{*}{ Parte superior } & & & & & & & & & & & & & & : & & & & & & & & \\
\hline & & & & & & & & & & & & & & & & & & $\therefore$ & & & & & & & \\
\hline 23 & Bultynck (1971) & Fm. Cañamares & & & & & & & & ; & & & & & 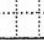 & 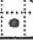 & & $\because$ & & & & & & 1 & \\
\hline \multirow[t]{2}{*}{24} & Carls(1977) & & $\begin{array}{c}\text { Base } \\
\text { Partc super }\end{array}$ & & & & & & & : & & & & & 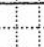 & & $\%$ & . & : & & & & & 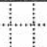 & \\
\hline & \multirow{2}{*}{\multicolumn{2}{|c|}{$\begin{array}{l}\text { Fm. Lussma } \\
\text { Sarmiento et al(1991)Fm. Guadarranquejo } \\
\text { Sarmiento et al(in lit)Calizascyphoorinitites }\end{array}$}} & Base & & & & & & & & & & & & 1 & & 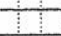 & & & & & & & & \\
\hline 26 & & & & & & & & & & 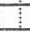 & & $\circ$ & & & & & & & & & & & & & \\
\hline \multirow{4}{*}{27} & \multirow{4}{*}{$\begin{array}{c}\text { Gnoli et al. (1990) } \\
\text { (entre otros) }\end{array}$} & \multirow{4}{*}{$\begin{array}{c}\text { Formación } \\
\text { Fluminimaggiore }\end{array}$} & Base & & & & & & & & & & & & 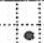 & & : & & • & & & & & : & \\
\hline & & & & & & & 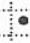 & & & - & & & & & & & $\bullet$ & & & & & & & & \\
\hline & & & & & & & & & & & & & : & & $\cdot$ & & 6 & & & & & & e: & & \\
\hline & & & & & & & & & & & & & & & & & & & & & & & & & \\
\hline 28 & Olivieri et al. (1980) & Fm.Fluminimaggiore & & & & & & & & & & I & & & 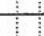 & & 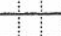 & $\div$ & 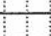 & 1 & & 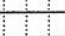 & & : & \\
\hline & Barca et al. (1986) & Grupo Serra S'Ilixi & Fivi & & & & & & & & & it & & & : & & $\cdot$ & & 11 & & & 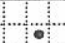 & & & \\
\hline & Barca ef al. (1994) & Genna,Ciucrciu,Siliu & & & & & & & & & & & & & & & & & & & & & & & \\
\hline
\end{tabular}




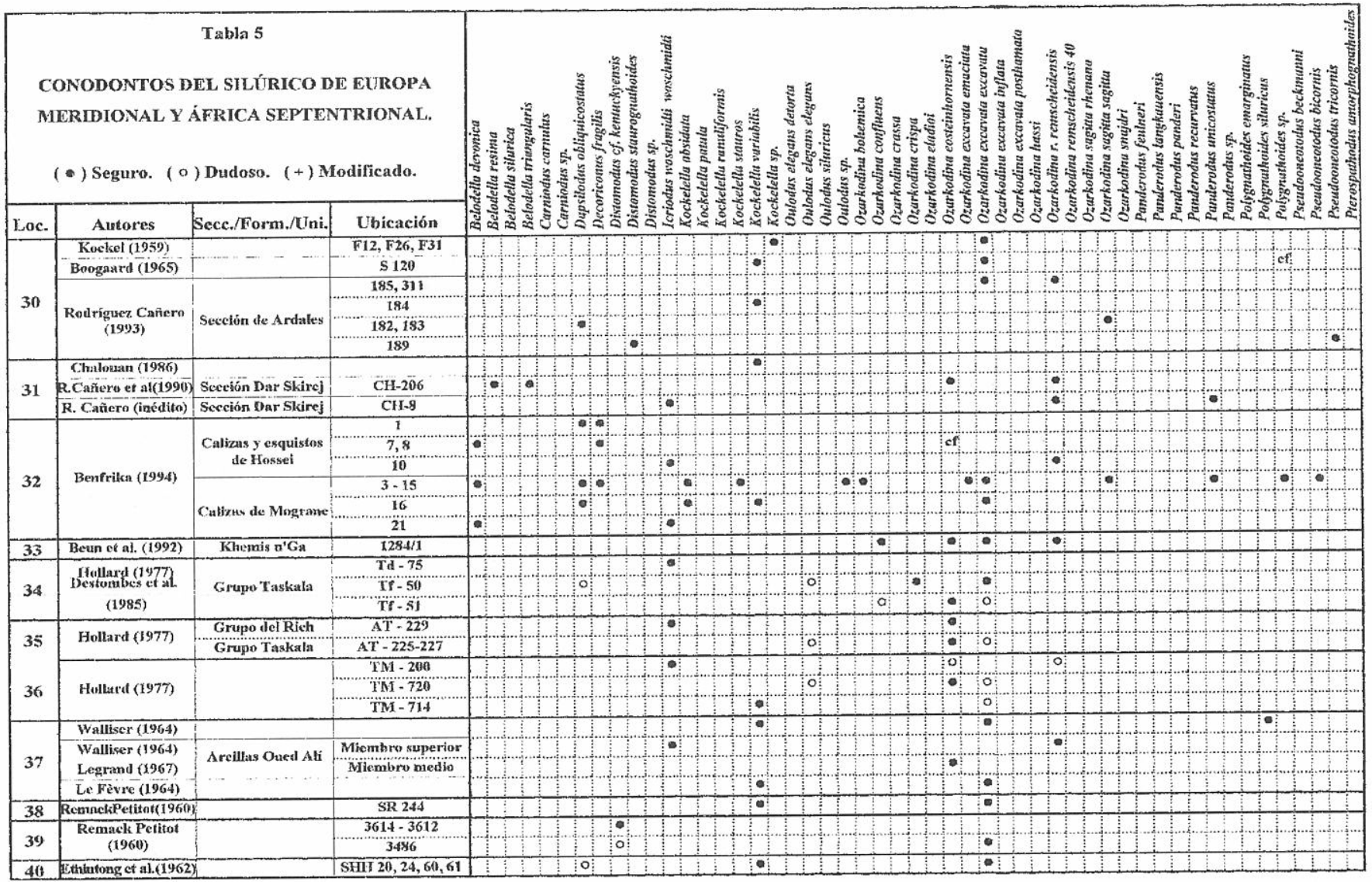

identificadas en cada una de las localidades quedan reflejadas en la Fig. 2, en donde las líneas de trazo continuo representan biozonas o cronozonas reconocidas y el punteado indica un horizonte $\mathrm{u}$ horizontes indeterminados dentro de las zonas correspondientes al intervalo señalado.

En gran parte del ámbito analizado, el Silúrico está separado del Ordovícico por una laguna de extensión variable, mientras que en algunos sectores parece que existe una continuidad sedimentaria entre ambos Sistemas. Tras este complejo tramo basal con discontinuidades, en la región se pueden distinguir asociaciones mayores de facies consistentes en pelitas que gradan de manera heterócrona a facies siliciclásticas groseras, a calizas de cefalópodos de rampa distal ( "facies mediterránea" auct.), o bien a calizas bioclásticas en áreas marginales. En la mayoría de los casos los conodontos son extraídos de rocas carbonatadas, de ahí que su presencia esté casi siempre vinculada con esta litología. En esta síntesis, el análisis de las asociaciones de conodontos, juntamente con el tipo de roca donde se encuentran, ha permitido reconocer y datar la existencia de episodios carbonatados. El estudio bibliográfico de los datos de graptolitos, muy abundantes en los materiales pelíticos, ha servido para contrastar o para facilitar la correlación de tales horizontes carbonatados en aquellos casos en que sus conodontos no aportaban precisiones suficientes para su asignación bioestratigráfica.

La información disponible sobre las características del Silúrico en las distintas áreas incluidas en esta síntesis es muy desigual, y en buena parte los datos de conodontos derivan de secuencias muy tectonizadas, lo que dificulta, en algunos casos, la reconstrucción de las sucesiones estratigráficas correspondientes. En otros, es posible disponer de columnas estratigráficas representativas de toda la secuencia silúrica y estimar el espesor total tanto de los materiales que la integran, como de las litofacies características (Figs. 3-7). Para facilitar la síntesis de los datos evaluados, aquellas secciones próximas, similares por sus caracteres litológicos y contenido en conodontos, se han agrupado dentro de la misma localidad, distinguiéndose un total de 40 sucesiones representativas de siete áreas: Francia, Pirineos, Cadenas Costeras Catalanas, Macizo Hespérico, Cerdeña, Maláguides y Africa septentrional, algunas de ellas subdividias en diferentes dominios estructurales (Figs.1-2).

\section{EUROPA MERIDIONAL}

\section{FRANCIA}

Los afloramientos silúricos de los macizos paleozoicos del norte de Francia exhiben una marcada heterogeneidad lateral y vertical dependiendo de su contexto estructural y paleogeográfico. Los depósitos silúricos se comportan como niveles de deslizamiento ya que las pizarras ampelíticas, por su menor competencia mecánica, favorecieron los despegues y fracturas que afectan a la mayor parte de los terrenos silúricos, ocasionando la supresión y/o repetición de tramos y, en consecuencia, la ausencia o repetición de biozonas. Los materiales silúricos en los que se han descrito conodontos corresponden a distintos dominios tectosedimentarios: $\mathrm{N}$ de 
Francia y Ardenas, el Macizo Armoricano y NO del Macizo Central , la Montaña Negra, el Macizo de Mouthoumet y los Pirineos.

\section{Norte de Francia y Ardenas}

Las Ardenas francesas, que forman parte del sistema imbricado de cabalgamientos septentrional varisco, constituyen el sector más septentrional con conodontos del ámbito analizado en esta síntesis. Los materiales silúrico-devónicos en Artois, en la prolongación occidental del borde norte del Sinclinorio de Dinant, corresponden a dos conjuntos sedimentarios superpuestos, el primero de los cuales está constituido por materiales arcillosos y carbonatados con abundantes fósiles marinos. El segundo conjunto es de carácter pizarroso y presenta algunos niveles arenosos. En este dominio la mayor parte de las observaciones provienen de labores mineras y de sondeos.

En el subsuelo de Artois (Figs. 1, 2; loc. 1. Tab. 1. Fig. 3; columna 1), Bultynck (1977, 1986) identificó conodontos en los niveles carbonatados arcillosos, en parte encriníticos, de la clásica "Série de Liévin". Las primeras descripciones de este autor proceden de distintos niveles atravesados por sondeos próximos a la localidad de Liévin, en tanto que las res- tantes provienen de la sección tipo de la Fm. Noulette, en el sondeo del mismo nombre. En estos materiales, que se reconocen actualmente como Miembro de Angres de la Fm. Noulette (Racheboeuf, 1986), existen conodontos indicativos del Prídoli (Zona de Ozarkodina eosteinhornensis) y del Lochkoviense basal (Zona de Icriodus woschmidti woschmidti). El $\mathrm{Mb}$. Angres (65 m) de la Fm. Noulette, con un espesor aproximado de unos $115 \mathrm{~m}$, constituye sólo la parte terminal del Silúrico, cuya base se desconoce, yaciendo en contacto tectónico (Falla del Midi) sobre sedimentos carboníferos.

En un sector relativamente próximo al anterior, como es el Macizo de Condroz, la secuencia silúrica (LlandoveryLudlow) está representada por más de $1000 \mathrm{~m}$ de sedimentos pizarrosos que alternan con areniscas de grano fino, en ocasiones con cemento carbonatado. Como información complementaria podemos señalar que en el Macizo de Brabant, el Llandovery se caracteriza por un conjunto pelítico, con intercalaciones cuarcíticas y niveles carbonatados, que alcanza $750 \mathrm{~m}$ de espesor, destacando la existencia de coladas riolíticas por encima de niveles atribuidos a la Zona de Coronograptus cyphus. La Serie Wenlock está representada por unos $400 \mathrm{~m}$ de filitas y calcoesquistos dolomíticos que incluyen niveles de areniscas finas, en parte calcáreas. Finalmente el Ludlow, con aproximadamente $1000 \mathrm{~m}$ de serie, está repre-

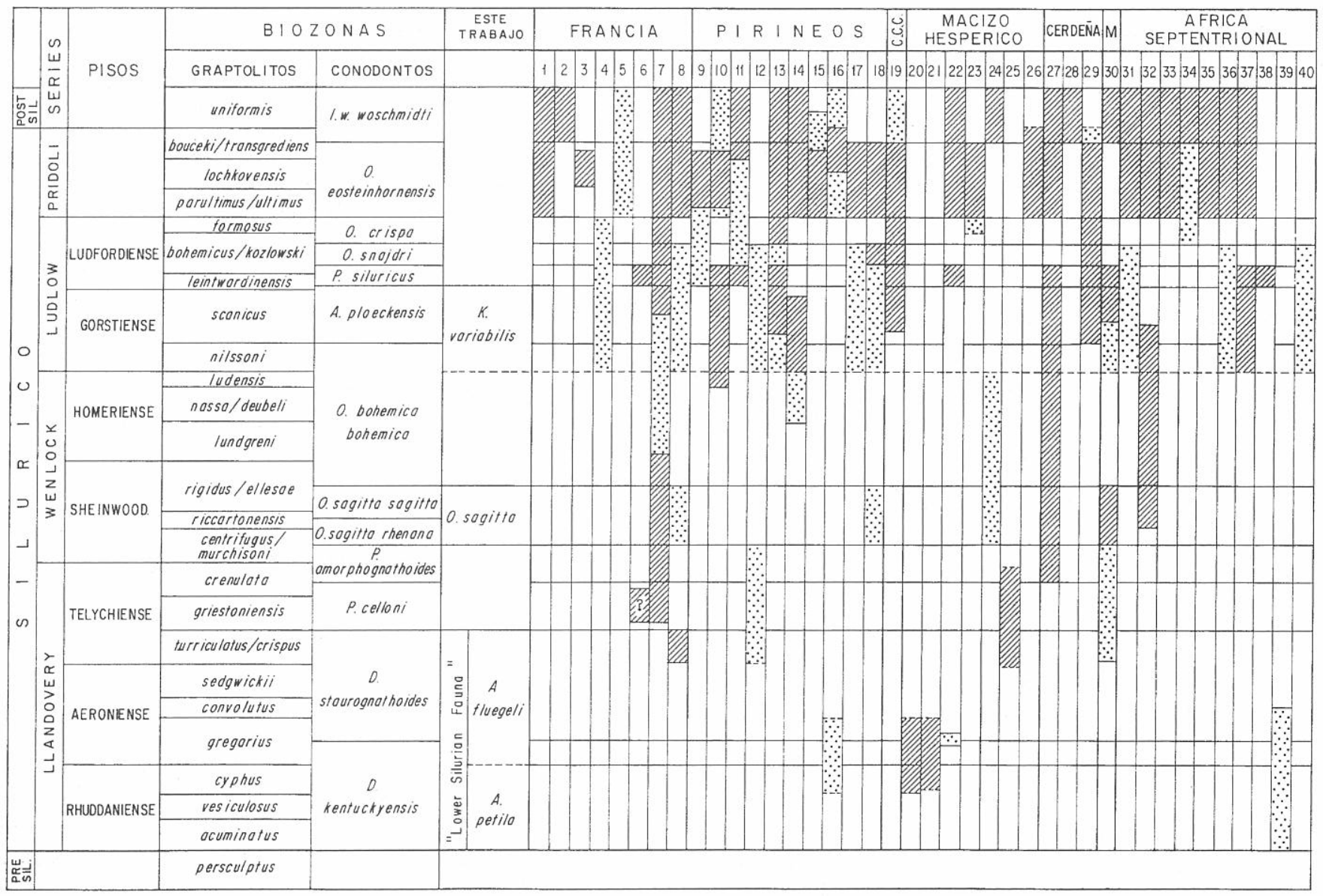

Figura 2. Zonas de conodontos reconocidas en las sucesiones silúricas del SO de Europa y N de África. Los números corresponden a las localidades de la Fig. 1. El punteado indica un horizonte u horizontes indeterminados dentro de las zonas correspondientes al intervalo señalado o atribuciones supuestas. En todas las localidades los conodontos fueron extraídos de rocas carbonatadas, excepto en las Locs. 24 y 25 que son silicilásticas (Modificado de García- López et al., 1994). 
sentado por cuarzofilitas y areniscas de grano muy fino. Si bien estos sectores quedan fuera del ámbito de nuestro estudio, la información que aportan permite inferir la existencia de una cuenca muy subsidente, con un neto predominio de materiales clásticos finos, así como episodios volcánicos en el Llandovery temprano.

En el borde SE del Macizo de Rocroi (sinclinorio de Neufchâteau) aflora, discordante sobre las rocas cámbricas, la Formación Fépin con un espesor aproximado de $50 \mathrm{~m}$ en la localidad de Naux (Figs. 1, 2; loc. 2. Tab. 1. Fig. 3; columna 2). Esta unidad, con una base conglomerática y constituida principalmente por pizarras negras, incluye a techo materiales carbonatados encriníticos (Caliza de Naux), de $2.75 \mathrm{~m}$ de potencia y geometría lenticular. La base de esta caliza no está expuesta, habiéndose señalado un hiato de $1.75 \mathrm{~m}$. En estos niveles, Bender (1967) identificó conodontos de la Zona de I. w. woschmidti. Con posterioridad, Bultynck (1982), Borremans y Bultynck (1986) obtuvieron conodontos de quince muestras de tres secciones muy próximas entre sí (A, B, C), lo que les permitió ampliar la información sobre los conodontos de esta caliza, que correlacionaron con la asociación mas moderna del Miembro de Angres de la Fm. Noulette.

\section{Macizo Armoricano y NO del Macizo Central}

A diferencia de las facies más profundas de las Ardenas, la sedimentación silúrica en el Macizo Armoricano denota un mayor influjo clástico y presenta afloramientos más extensos. Las facies de ampelitas de algunas decenas de metros, depositadas generalmente entre el Llandovery y el Ludlow, son sucedidas por centenares de metros de lutitas y areniscas con una subsidencia alta en los dominios de Normandía septentrional y centro-norte armoricano. El límite Ordovícico/ Silúrico está marcado en la mayor parte del Macizo Armoricano por diversas lagunas estratigráficas.

El Silúrico de Bretaña, Normandía y SE del Macizo Armoricano comprende dos dominios paleogeográficos diferenciados a ambos lados del eje de Lanvaux, vigentes desde el Ordovícico hasta el Devónico. Al norte del mismo (Normandía, Sinclinorio Central Armoricano, Sinclinales del sur de Rennes), el Silúrico se inicia con unidades arenosas en las que se intercalan niveles ampelíticos que constituirán la litología dominante en el Wenlock. Con posterioridad, estas facies de pizarras negras tienden a dar paso a una alternancia pizarroso-arenosa que prosigue con continuidad aparente hasta el tránsito Silúrico-Devónico.

En Cotentin, las pizarras negras ampelíticas del Wenlock y Ludlow incluyen algunos niveles con nódulos silico-arcillosos y calcáreos; en tanto que en la Serie Wenlock de los sinclinales de May y Urbille, al S de Caen, se presenta un nivel carbonatado negro con ortocerátidos.

En la Península de Crozon (Punta de Lostmarc'h) del Sinclinorio Central Armoricano, la sucesión silúrico-devónica (Figs. 1, 2; loc. 3. Tab. 1. Fig. 3 ; columna 3), está constituida por pizarras negras y bancos de cuarcita con nódulos e intercalaciones de niveles carbonatados decalcificados. En los primeros Bultynck y Pelhate (1971) identificaron conodontos de la Zona de O. eosteinhornensis, en niveles situados entre las ampelitas del Ludlow y Prídoli (con Pristiograptus vulgaris, Bohemograpthus bohemicus, Lobograptus scanicus y Pseudomonoclimacis ultimus) y los "Esquistos y Cuarcitas de Plougastel" del Lochkoviense. Los conodontos descritos por los autores citados provienen de un banco carbonatado fosilífero con ortocerátidos y algunos bivalvos (Posidonia eugyra).

Al sur del eje de Lanvaux, en el Dominio del Loira, la sedimentación lutítico-arenosa comienza ya en el Ordovícico superior, continúa durante el Silúrico en el complejo volcano-sedimentario de Saint-Georges-sur-Loire y termina en el Devónico Inferior. Este complejo, en facies flysch, contiene importantes manifestaciones volcánicas de tipo espilita-queratófido.

La secuencia silúrica de la Unidad de Ancenis es por el contrario menos potente y exhibe una mayor diversidad litológica, incluyendo sedimentos carbonatados silúrico-devónicos. Al sur del Macizo Armoricano, en el Dominio de Vendée, los depósitos pizarroso-arenosos alternan, en distintas localidades, con ampelitas, liditas y carbonatos, registrándose ocasionalmente la presencia de intercalaciones riolíticas de edad Wenlock.

En el Sinclinorio de Angers las sucesiones también son poco potentes e intercalan calizas ampelíticas en el Silúrico superior dentro de una secuencia esquistosa. Lys y Mauvier (1967) señalan la presencia en ellas de conodontos silúricos (Figs. 1, 2; loc. 4. Tab. 1. Fig. 3; columna 4). La ausencia de especies características impide precisar la edad de estos materiales, que asignamos al Ludlow.

En el NO del Macizo Central, Guillot y Le Fèvre (1975) mencionan la presencia de conodontos en un pequeño lentejón carbonatado intercalado entre los esquistos sericíticos de la unidad de Génis, que forman parte de la serie metamórfica del Bas-Limousin (Figs. 1, 2; loc. 5. Tab.1. Fig. 3; columna 5). Los conodontos presentan una conservación muy deficiente y se hallan muy alterados, por lo que su identificación sólo fue posible en nomenclatura abierta. No obstante, los autores citados los atribuyen al intervalo Silúrico superior-Devónico Inferior.

\section{S del Macizo Central: Montaña Negra}

La Montaña Negra consta de tres grandes unidades geológicas: la central o zona Axial metamórfica, la septentrional y la meridional, estas últimas caracterizadas por un conjunto de láminas cabalgantes hercínicas. En el sector septentrional (Figs. 1, 2; loc. 6. Tab. 1. Fig. 3; columna 6), las rocas silúricas afloran tan sólo en Murasson y fueron analizados por Centène y Sentou (1975). La secuencia silúrica, con un espesor aproximado de $165 \mathrm{~m}$, se dispone mediante contacto tectónico sobre los depósitos del Ordovícico inferior; a techo, y también mediante contacto tectónico sobreyacen las pizarras arenosas del Cámbrico. La sucesión se inicia con un conjunto de bancos decimétricos de calizas recristalizadas, de unos $20 \mathrm{~m}$ de espesor, que son referidas a la Zona de Pterospathodus celloni (Llandovery superior). Esta atribución, basada en un único morfotaxón, debe de ser considerada sólo como tentativa, siendo necesario otros argumentos paleontológicos para confirmarla. Por el contrario, la Zona de Polygnathoides siluricus (Ludlow) está bien documentada en los tramos medios y superiores de la secuencia donde existen bancos calcáreos con ortocerátidos y niveles con nódulos carbonatados intercalados entre esquistos negros. En estos últimos es 
frecuente la presencia de Cardiola interrupta, braquiópodos y ortocerátidos.

En el sector meridional de la Montaña Negra (Figs. 1, 2; loc. 7 Tab. 1. Fig. 3; columna 7), los terrenos silúricos aparecen expuestos en varias de las unidades de Cabriéres. Sólo a través de los estudios bioestratigráficos, con graptolitos y conodontos, ha sido posible reconstruir la sucesión estratigráfica en este sector, donde los afloramientos son muy fragmentarios. La secuencia silúrica yace en contacto normal sobre los depósitos del Ashgill, y sobre ella se disponen en continuidad sedimentaria los materiales del Devónico. Esta última relación fue demostrada por Feist y Schönlaub (1974) en el norte del "plateau" de Falgairas.

Las asociaciones de conodontos del Silúrico de este sector han sido estudiadas en detalle por Feist y Schönlaub (op. cit.) y por Centène y Sentou (1975). Los datos obtenidos permiten reconocer varias zonas de conodontos en un amplio intervalo temporal (Llandovery superior-Prídoli) pese al carácter discontinuo de los afloramientos que impide disponer de una única sección de referencia. Sin embargo, los estudios bioestratigráficos realizados con graptolitos y conodontos posibilitan la reconstrucción litoestratigráfica del Silúrico en este dominio. Así, en Gabian se hallan expuestos $40 \mathrm{~m}$ de pizarras negras del Llandovery, que en su base incluyen nódulos carbonatados con conodontos de la Zona de Pterospathodus celloni (Llandovery superior). Las pizarras suprayacentes han proporcionado graptolitos de la Zona de Spirograptus turriculatus (Telychiense basal). Esta aparente contradicción puede ser debida a una inversión de la sucesión por fracturas. El control bioestratigráfico con graptolitos permite inferir la repetición de partes de esta secuencia y estimar que su potencia real no excede de $15 \mathrm{~m}$. En las proximidades de Roquemaillère los depósitos silúricos se inician con pizarras del Llandovery, que son sucedidas por una alternancia de pizarras (con Monograptus priodon y Retiolites geinitzianus) y niveles o nódulos carbonatados con ortocerátidos, braquiópodos y trilobites del género Aulacopleura, que contienen conodontos de la Zona de Ozarkodina sagitta. El espesor estimado para este conjunto es de unos $40 \mathrm{~m}$. En el norte del "plateau" de Falgairas, las secciones de la Rouquette, Orte y Tiberet, con potencias de 30, 50 y 15 m respectivamente, muestran un predominio de los materiales carbonatados sobre los clásticos. La primera sección se inicia con bancos calcáreos y niveles pizarrosos con $M$. priodon y conodontos de la Zona de Pterospathodus amorphognathoides, a los que suceden calizas y niveles margosos con nódulos carbonatados que contienen ortocerátidos y Cardiola, además de conodontos de la Zona de $O$. sagitta. La sucesión prosigue con dolomías brechoides, pizarras arenosas y niveles carbonatados con conodontos indicativos de la Zona de Ozarkodina snajdri (por la presencia de Pedavis latialata); en estos últimos niveles se han descrito morfotaxones que pueden corresponder a Ozarkodina eosteinhornensis. En la misma localidad, Feist y Schönlaub (1974) citan la presencia de O. sagitta sagitta y $O$. s. bohemica. Sobre estos materiales, otros niveles carbonatados, en parte dolomíticos, contienen $P$. siluricus. En la sección de Orte, un conjunto, de unos $30 \mathrm{~m}$ de espesor, de calizas y margas han proporcionado conodontos de las Zonas de O. sagitta, O. crispa y O. eosteinhornensis, en tanto que en Tiberet está representada la Zona de Icriodus woschmidti woschmidti del Lochkoviense basal.

\section{Macizo de Mouthoumet}

El Macizo de Mouthoumet se sitúa entre la Montaña Negra y los Pirineos Orientales. En él, se distinguen un conjunto de láminas hercínicas donde las rocas silúricas han actuado como nivel de despegue. Como consecuencia de ello, los afloramientos son muy discontinuos y sólo a través de estudios estratigráficos y paleontológicos de detalle (de carácter puntual), ha sido posible reconstruir una sucesión tipo. En este sentido, los trabajos de Ovtracht (1964), Centène y Sentou (1975) y Dégardin (1988), han constituido un valioso aporte para establecer la secuencia temporal de los depósitos silúricos en este macizo hercínico (Figs. 1, 2; loc. 8 Tab. 1. Fig. 3; columna 8). De la integración de los datos procedentes de las secciones de Termes, Courtals, Cascatel, Albas y Félines, podemos estimar para los depósitos silúricos una potencia próxima a los $120 \mathrm{~m}$. La sedimentación silúrica se inicia en este área con pizarras negras del Llandovery, que alcanzan un espesor aproximado de 30 m. Dégardin (1988), citó una sección en donde las pizarras negras incluyen graptolitos de las Zonas de Monograptus convolutus y Stimulograptus sedgwickii del Aeroniense, refiriendo en los niveles carbonatados suprayacentes la presencia del morfotaxón Neoprioniodus planus. Este se considera actualmente como el elemento $\mathrm{M}$ de $A$. fluegeli, por lo que su hallazgo podría representar la parte superior de la zona homónima.

A estos niveles les suceden pizarras con nódulos y bancos carbonatados, en parte dolomíticos, con conodontos que pueden adscribirse a las especies de O. sagitta sagitta, O. s. rhenana y $K$. variabilis. En Courtals, Albas y Félines, la sucesión silúrica culmina con horizontes de nódulos calcáreos con conodontos de las Zonas de O. eosteinhornensis e $I$. w. woschmidti, que documentan la continuidad sedimentaria a través del límite Silúrico-Devónico.

\section{PIRINEOS}

El orógeno alpino del Pirineo está caracterizado por un apilamiento antiformal central o Zona Axial primaria, que involucra a la mayoría de las rocas paleozoicas y que constituye en realidad parte del sistema de cabalgamientos vergentes al sur de la cadena pirenaica. El sistema septentrional incluye los afloramientos de los macizos norpirenaicos y vascos.

El Silúrico "clásico" de los Pirineos corresponde a las "Pizarras con graptolítidos" de Schmidt (1931), unidad litológica atribuida al intervalo Rhuddaniense superior-Gorstiense (Dégardin, 1988). La base del Silúrico no se conoce y podría colocarse por debajo de las ampelitas que generalmente están despegadas de las formaciones del Ordovícico superior. En alguna localidad se ha descrito su posible transición con lutitas presumiblemente ordovícicas (Dégardin, op. cit.) y en el área meridional del Pirineo existe una cuarcita delgada (8-20 m) bajo las ampelitas, donde no se han puesto de manifiesto discontinuidades o hiatos. Las datos paleontológicos más antiguos proceden de este área (Estana, Loc. 15), en donde Dalloni (1930) citó graptolitos del Rhuddaniense inferior-medio y Boissevain (1934) asignó las ampelitas, situadas sobre las cuarcitas, al Rhuddaniense superior- Aeroniense. Por otro lado, Llopis Lladó (1966) describió una potente sucesión de pizarras azules y negras alternando con areniscas en Encamp 


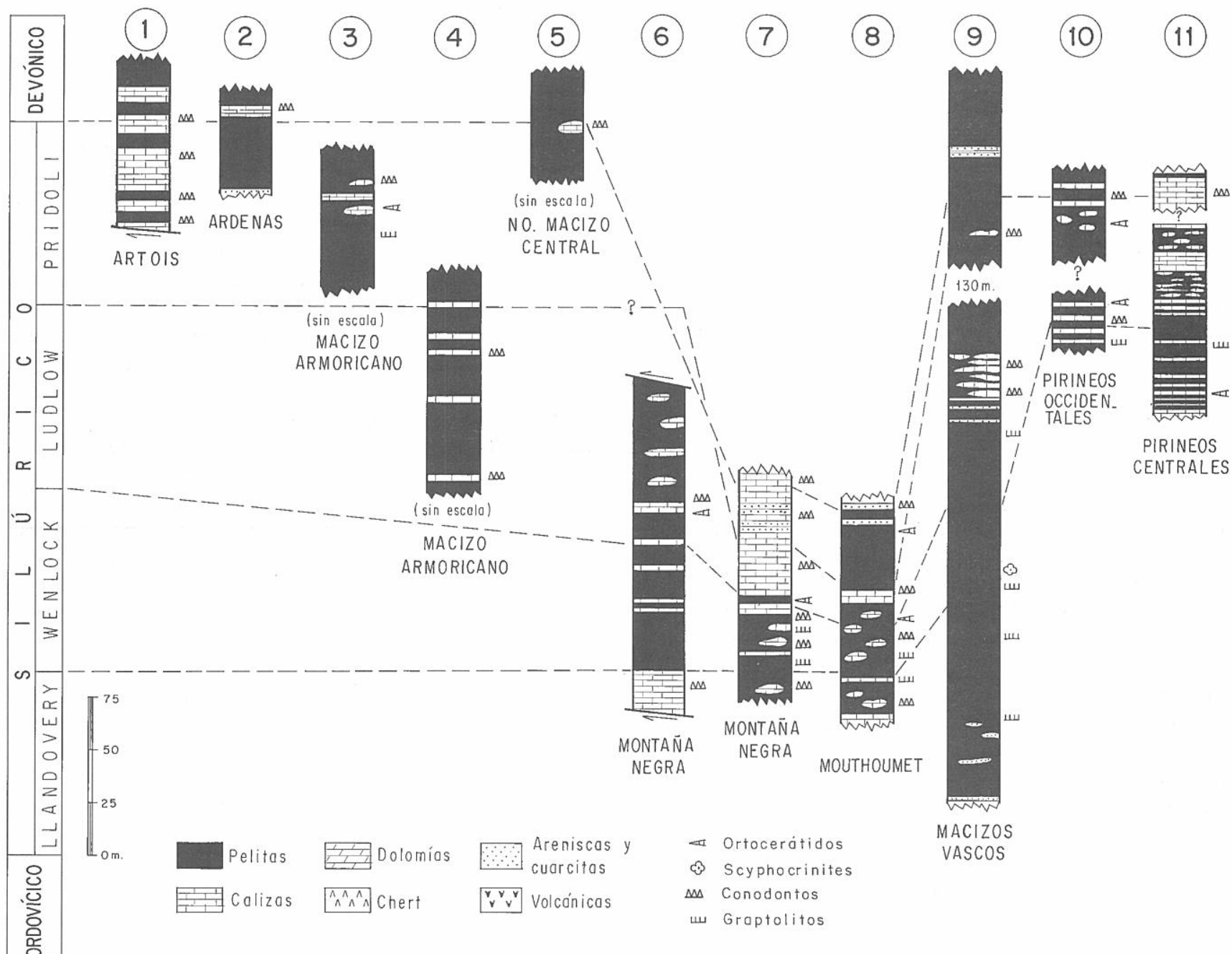

Figura 3. Sucesiones estratigráficas sintéticas del Silúrico (columnas 1-11) en N de Francia y Ardenas, Macizo Armoricano, NO de Macizo Central, Montaña Negra, Macizo de Mouthoumet, Macizos vascos, Pirineos occidentales y Pirineos centrales. Los números corresponden a las localidades de la Fig. 1.

(Andorra, Loc. 13) que contienen graptolitos atribuidos al Rhuddaniense medio-superior. Más recientemente en la collada de Toses (Loc. 16) Sanz-López y Sarmiento (inédito) encontraron conodontos en margas con nódulos calcáreos, situadas entre areniscas y rocas volcanoclásticas, que indican posiblemente el tránsito Rhuddaniense-Aeroniense. El límite Silúrico-Devónico será tratado en cada una de las áreas geográficas diferenciadas dentro del Pirineo.

\section{Macizos vascos}

Las sucesiones silúricas de los Pirineos vascos (Figs. 1, 2; loc. 9. Tab. 1. Fig. 3; columna 9) son esencialmente ampelíticas, y muestran potencias muy variables con tendencia a disminuir hacia el norte y el este. Así, las lutitas basales con niveles limolíticos alcanzan $200 \mathrm{~m}$ en Aldudes (Heddebaut, 1975), mientras que en Jarra su potencia es de 80 a 100 m y contienen graptolitos del Aeroniense (Dégardin, 1979).

En el macizo de Aldudes, Klarr (fide Requadt, 1974) distinguió la Fm. Arnéguy cuya parte inferior está compuesta por
150-180 m de ampelitas que intercalan hacia el techo lentejones calcáreos. Estos carbonatos contienen O. eosteinhornensis (Requadt, 1974) y elementos asignables a $K$. variabilis obtenidos en el valle de Arizakun (Juch y Schäfer, 1974). La potencia de las ampelitas disminuye a 80-110 m en los afloramientos orientales de Jarra. En ellas, Dégardin (1988) señaló la presencia de capas delgadas de areniscas finas con graptolitos del Gorstiense, y niveles carbonatados con ortocerátidos, asî como la existencia de lobolitos de Scyphocrinites stellatus mutabilis en el Wenlock inferior. La parte superior de la Fm. Arneguy, entre el Prídoli y Lochkoviense, está formada por lutitas azules o verdes con niveles subordinados de areniscas finas y alguna cuarcita. El conjunto presenta variaciones de espesor, desde 100 a 350 (Heddebaut, 1975) a los más de 640 m estimados por Requadt (1974) en el macizo de Aldudes.

\section{Pirineos occidentales}

Las potentes sucesiones silúricas de los Macizos vascos contrastan con las otras sucesiones pirenaicas. En los Piri- 
neos occidentales, sobre las ampelitas graptolíticas (con espesores entre 70 y $180 \mathrm{~m}$ ) hay un tramo decamétrico de calizas con ortocerátidos. En el Valle de Tena (Figs. 1, 2; loc. 10. Tabs. 1, 2. Fig. 3; columna 10), Dégardin (1988) citó graptolitos pertenecientes a las Zonas de Cyrtograptus ellesae y $C$. lundgreni. Los carbonatos de los niveles suprayacentes están representados por capas, lentejones o nódulos con ortocerátidos, intercalados entre pelitas negras. Su base corresponde a un nivel previo a la Zona de $K$. variabilis y alcanzan la parte superior o un horizonte posterior a la Zona de P. siluricus, según datos obtenidos en el barranco de S. Lorenzo (Valenzuela-Ríos, inédito). En Sandiniés un tramo pelítico separa estas calizas, de otras ampelitas que contienen nódulos carbonatados con conodontos del Prídoli, seguidos por dos bancos de calizas con I. woschmidti (Dégardin y Lethiers, 1982).

\section{Pirineos centrales}

Los materiales silúricos que afloran con gran extensión cerca de Benasque, sobre todo en la Sierra Negra, están constituidos por una alternancia de ampelitas y calizas con ortocerátidos (Figs. 1, 2; loc. 11. Tab. 2. Fig. 3; columna 11). Dégardin y Waterlot (1974) describieron localmente dicha alternancia por debajo de unas ampelitas que contienen graptolitos de las Zonas de C. ellesae y C. lundgreni. Por encima de estos niveles ampelíticos hay un predominio de los materiales carbonatados, al menos desde la Zona de P. siluricus (Sanz, inédito), constituyendo un tramo que puede seguirse cartográficamente. La sucesión silúrica culmina con 10-16 m de calizas o capas delgadas de calizas y margas, que a techo han proporcionado conodontos del Prídoli terminal, como Ozarkodina del grupo remscheidensis, O. eladioi e I. woschmidti woschmidti (Dégardin, 1988; Dégardin y Paris, 1978; Valenzuela-Ríos, 1994)

El sinclinorio de Llavorsí, constituye la continuación de la unidad de Sierra Negra y junto a la zona de Llessui y el sinclinorio de Tor en Andorra, se han incluido en la misma localidad (Figs. 1, 2; Loc. 13. Tab. 3. Fig. 4; columna 13). Aunque existen algunas intercalaciones de calizas de edades Homeriense y Gorstiense basal, el tramo más importante de calizas con ortocerátidos parece desarrollarse por encima de estos niveles, que en Llessui corresponden a las margas con Encrinurus rialpensis de Schmidt (1931). Estos materiales, que contienen tambien Camarocrinus subornatus, han proporcionado K. variabilis en Fontaneda y P. siluricus en Pal (Buchroithner, 1979). Además, en Llessui, Dégardin (1988) identificó $O$. crispa y $O$. eosteinhornensis. La parte alta de la sucesión está constituida por calizas con intercalaciones pelíticas y ampelitas con nódulos carbonatados, que en diversas localidades Buchroithner (1979) y Dégardin (1988) asignaron a la Zona de O. eosteinhornensis. En el techo de la sucesión, en Pal, la presencia del dacrioconárido Nowakia sp. permite su asignación al Devónico, mientras que en Fontaneda, Civís y Port Negre, Dégardin (1988) citó I. woschmidti. Un punto de discusión es la potencia de la unidad con carbonatos, que oscila entre 10 y $50 \mathrm{~m}$ en diferentes localidades para Dégardin (1988) y los menos de 10 m estimados en Encamp (Llopis-Lladó, 1966) o en Pal (Buchroithner, 1979).

Los materiales silúricos de la parte septentrional de la Zona Axial pirenaica son similares a los descritos en los piri- neos centrales. Sin embargo, al norte del macizo de Lys-Caillouas, Dégardin (1988) y otros autores, señalaron la presencia de capas de caliza intercaladas hacia la base del Sistema. Estas observaciones pueden estar relacionadas con la existencia de una sucesión condensada de carbonatos, descrita por Palau y Sanz (1989) entre los batolitos del Marimanya y Bassiès (Figs. 1, 2; loc 12. Tab. 3. Fig. 4; columna 12). Esta sucesión consta de $2 \mathrm{~m}$ de ampelitas y calizas encriníticas con corales, fenéstelidos y conodontos como $K$. cf. ranuliformis (Llandovery superior a Wenlock inferior). Por encima se disponen calizas negras con crinoideos y ortocerátidos, donde se ha obtenido $K$. cf. variabilis.

Los afloramientos de Les Nogueres (Figs. 1, 2; loc. 14. Tab. 3. Fig. 4; columna 14), se centran sobre todo en la unidad de Castells. La sección más detallada de Llopis-Lladó y Rosell Sanuy (1968), está constituida por ampelitas y algunas capas centimétricas de carbonatos, más potentes hacia el techo, con graptolitos correspondientes al intervalo entre las Zonas de Monograptus crispus y Neodiversograptus nilssoni. En la sección de Baén, Dégardin (1988) destacó en el Homeriense (Zona de Cyrtograptus lundgreni) unas calizas negras (4-5 m ) por debajo de lutitas negras $(40 \mathrm{~m})$ con carbonatos que contienen $O$. bohemica, que este autor asignó al Gorstiense. Hacia la parte alta de la sucesión hay un predominio de calizas nodulosas con ortocerátidos (Llopis Lladó y Rosell Sanuy, op. cit.), que están separadas de un horizonte carbonatado por ampelitas con graptolitos de la Zona de Lobograptus scanicus. Esta sucesión es posiblemente comparable a la descrita en Surroca por Buchroithner et al. (1978), en donde unas calizas de 1-3 m de potencia intercaladas en una sucesión pizarrosa, proporcionaron K. variabilis. Estos últimos autores tambien mencionaron, cerca de Castells, lutitas con nódulos y capas de calizas con conodontos del Prídoli. Finalmente, Llopis Lladó y Rosell Sanuy (1968) describieron una secuencia de calizas, lutitas con Scyphocrinites elegans y niveles alternantes, posiblemente comparable con los tramos que en Baén contienen fauna de la Zona de I. postwoschmidti (Boersma, 1973), o en la sección de Gerri corresponden a los intervalos $O$. remscheidensis $40+I$. $w$. woschmidti y $O$. carls $i+I$. w. transiens (Valenzuela-Ríos, 1994).

\section{Pirineos orientales}

La sucesión en el valle del Segre (Figs. 1, 2; loc. 15. Tab. 3 . Fig. 4; columna 15), muestra ciertas similitudes con la de Les Nogueres en los Pirineos Centrales, aunque se trata de afloramientos discontinuos e incompletos. Sobre unos 100-140 m de ampelitas que alcanzan la Zona de N. nilssoni en la localidad de Toloriu, se dispone un conjunto con alternancia de ampelitas y carbonatos. En Torres, Schmidt (1931) diferenció en este tramo de base a techo : Caliza con "Orthoceras" del Ludlow, Pizarras de graptolitos superiores y una caliza marrón de $4 \mathrm{~m}$ de espesor. En cambio, para Dégardin (1988), en la misma localidad, el tramo superior está constituido por 20-30 m de ampelitas muy deformadas, con nódulos carbonatados que contienen O. eosteinhornensis. Por otro lado, en Toloriu, se ha diferenciado la caliza del mismo nombre, constituida por $18 \mathrm{~m}$ de calizas nodulosas pardas con conodontos de la Zona de O. eosteinhornensis (Boersma, 1973) y que Valenzuela-Ríos (inédito) asigna al Prídoli más 
alto. Por encima, Schmidt (1931) y Dégardin (1988) describieron una alternancia de 5-10 m de ampelitas y calizas del Lochkoviense.

En la collada de Toses (Figs. 1, 2; loc. 16. Tab. 3 . Fig. 4; columna 16), se han encontrado nódulos carbonatados del Llandovery, dentro de una sucesión presumiblemente ordovícica, con Panderodus unicostatus, Walliserodus blackstonensis, W. santiclairi y Aspelundia cf. petila (Sanz-López y Sarmiento, inédito), representando las Zonas de A. petila y/o A. fluegeli basal. Además se han integrado, en la misma localidad, varios afloramientos dispersos al sur del Canigó. La sucesión de Camprodon muestra una potencia menor que en el Segre (Dégardin, 1988) y un tramo final con un incremento progresivo en carbonatos. Faura i Sans (1913) refieren en estas calizas la presencia de ortocerátidos, braquiópodos, bivalvos, gasterópodos, Scyphocrinus y espongiarios. En ellas se han encontrado conodontos como O. eladioi (Prídoli-Lochkoviense) por debajo de especies lochkovienses (Sanz-López, inédito).

Por otra parte, en la base de algunas láminas cabalgantes en Castellar de N' Hug y localmente en Camprodon, se observan calizas bioclásticas por debajo de una alternancia de ampelitas y calizas. Las primeras contienen gran cantidad de ortocerátidos, crinoideos, algunos braquiópodos y ostrácodos, encontrándose en las calizas encriníticas de Pla d' Anyella conodontos que pueden atribuirse al Prídoli más alto; las ampelitas y calizas corresponden al Lochkoviense conforme al hallazgo de conodontos de la Zona de Ancyrodelloides delta (Sanz-López, inédito). De esta misma sección procede $I$. woschmidti ssp. (Boersma, 1973). Una capa decimétrica de calizas bioesparíticas, en la sección de Les Feixes, ha proporcionado conodontos del Prídoli terminal, además de $O$. remscheidensis que indica, posiblemente, un horizonte muy próximo a la base del Devónico (Sanz-López, inédito).

Los terrenos silúricos del Sinclinal de Villefranche de Conflent al noroeste del Canigó (Figs. 1, 2; loc. 17. Tab. 3 . Fig. 4; columna 17), fueron estudiados por Centène y Sentou (1975) y Dégardin (1988). Aquí, el Silúrico está representado por una sucesión de $50 \mathrm{~m}$ de pizarras negras que en los tramos medio y superior incluyen nódulos y niveles carbonatados fosilíferos. De los primeros nódulos se obtuvieron conodontos (Dégardin, 1988) correspondientes al intervalo entre las Zonas de $K$. variabilis y $O$. snajdri. Los nódulos carbonatados de los niveles superiores contienen conodontos indicativos de la Zona de O. eosteinhornensis. Más arriba se disponen las calizas masivas del Devónico Inferior.

En Aspres (Figs. 1, 2; loc. 18. Tab. 3 . Fig. 4; columna 18), situado al noreste del Macizo de Canigó, los materiales silúricos están constituidos por una sucesión de pizarras, con intercalaciones de nódulos y bancos de calizas cuya potencia varía entre 20 y $50 \mathrm{~m}$. En las proximidades de Castelnou, los materiales carbonatados han proporcionado conodontos indicativos del Wenlock, Ludlow y Prídoli.

\section{CADENAS COSTERAS CATALANAS (CCC)}

Las Cadenas Costeras Catalanas son dos alineaciones montañosas que se orientan paralelamente a la costa mediterránea del NE de España. Los afloramientos con rocas silúricas tienen en este sector una distribución puntual, si bien pre- sentan características bastante homogéneas (Figs. 1, 2; loc. 19. Tab. 3 . Fig. 4; columna 19). La parte inferior de la sucesión silúrica está constituida por lutitas negras, con una potencia estimada entre 150 a $300 \mathrm{~m}$ cerca de Barcelona (Julivert et al., 1985), aunque Puschmann (1968) le asignó tan solo $40 \mathrm{~m}$ hasta el Wenlock superior en el Avencó (Montseny). Este autor señala la presencia de Parakidograptus cf. acuminatus (Rhuddaniense inferior) en unas lutitas arenosas sobre las que se disponen lutitas con graptolitos del Rhuddaniense medio-superior. En cambio para Julivert et al. (op. cit.), la sucesión silúrica comienza por una cuarcita de 20-25 $\mathrm{m}$ de espesor y continúa por ampelitas, que contienen capas de chert y rocas volcánicas básicas a intermedias, con graptolitos del Rhuddaniense superior al Aeroniense superior. El Wenlock está representado por ampelitas con graptolitos, que contienen hacia la base capas centimétricas de cuarcitas, mientras que en la parte alta predominan lutitas negras con capas y nódulos de sulfuros (Julivert et al., 1985). Sobre esta unidad se dispone una Formación de calizas (con texturas mudstone a wackestone) que intercalan niveles delgados de lutitas amarillentas y rojizas (Fm. La Creu, Julivert et al., op. cit.). El tránsito entre las ampelitas del Wenlock y las calizas de la Fm. La Creu es gradual. Los niveles alternantes contienen graptolitos del Gorstiense (Zona de L. scanicus) y del Ludfordiense basal como Saetograptus fritschi linearis (Zona de S. leintwardinensis), según datos obtenidos, respectivamente, en las localidades de San Vicens ( Julivert et al., 1985) y Turó de la Montcada (Greiling y Puschmann, 1965).

Los datos de conodontos más antiguos proceden de unas calizas removilizadas en la Serra de Miramar, donde Sanz (en Melgarejo, 1992) señaló la presencia de Ozarkodina excavata posthamata atribuida a la parte superior de la Zona de $K$. variabilis/A. ploeckensis. El resto de las biozonas de conodontos correspondiendo al intervalo entre la base de la Zona de $P$. siluricus y el techo de la Zona de O. eosteinhornensis, han sido identificadas, en las localidades de Santa Creu y Les Gavarres, (Walliser, 1964; Aldridge y Schönlaub, 1989; Sanz (inédito)). La base del Lochkoviense se sitúa tentativamente unos $10 \mathrm{~m}$ por debajo del techo de la Fm. La Creu en la localidad de Santa Creu (García-López et al., 1990); mientras que en otras localidades (Gavá, Cervelló y Serra de Miramar) el Lockoviense está representado por ampelitas que contienen Monograptus uniformis, según Julivert et al. (1985) y Ferrer et al. (1989).

\section{MACIZO HESPÉRICO}

Los terrenos paleozoicos que afloran en la mitad occidental de la Península Ibérica, constituyen el Macizo Hésperico o Macizo Ibérico (MI) y representan los afloramientos más occidentales del hercínico europeo. Hacia el E, el basamento paleozoico permanece oculto bajo una cobertera de sedimentos terciarios, con algunos fragmentos aflorando en el borde oriental de la Meseta Ibérica, integrados en un sistema de cabalgamientos y fallas inversas alpinas. El más importante es la Cordillera Ibérica (CI) o Celtiberia, constituida fundamentalmente por materiales mesozoicos con un núcleo paleozoico. Dentro del MI se reconocen varias Zonas diferentes, caracterizadas por rasgos propios de tipo estratigráfico, paleogeográfico, estructural y magmático: la Zona 
Cantábrica (ZC), la Zona Asturoccidental-Leonesa (ZAOL), la Zona Centroibérica (ZCI), la Zona de Ossa-Morena (ZOM), y la Zona Surportuguesa (ZSP). Donde la sucesión estratigráfica aparece más completa es en la ZC. En la ZAOL, ZCI y ZOM el Paleozoico Inferior adquiere gran desarrollo, en contraste con lo que sucede en el Paleozoico Superior, mientras que en la ZSP solo afloran estos últimos materiales.
En la Región de Pliegues y Mantos se encuentra la sucesión más completa del Silúrico constituida por dos unidades litoestratigráficas diferentes: una formación predominantemente pelítica (Fm. Pizarras de Formigoso), y una formación de areniscas ferruginosas (Fm. Furada/S. Pedro). La Fm. Formigoso alcanza un espesor de 70-200 m, y comprende pizarras negras o grises en la parte inferior, con niveles areniscosos intercalándose gradualmente y haciéndose más potentes

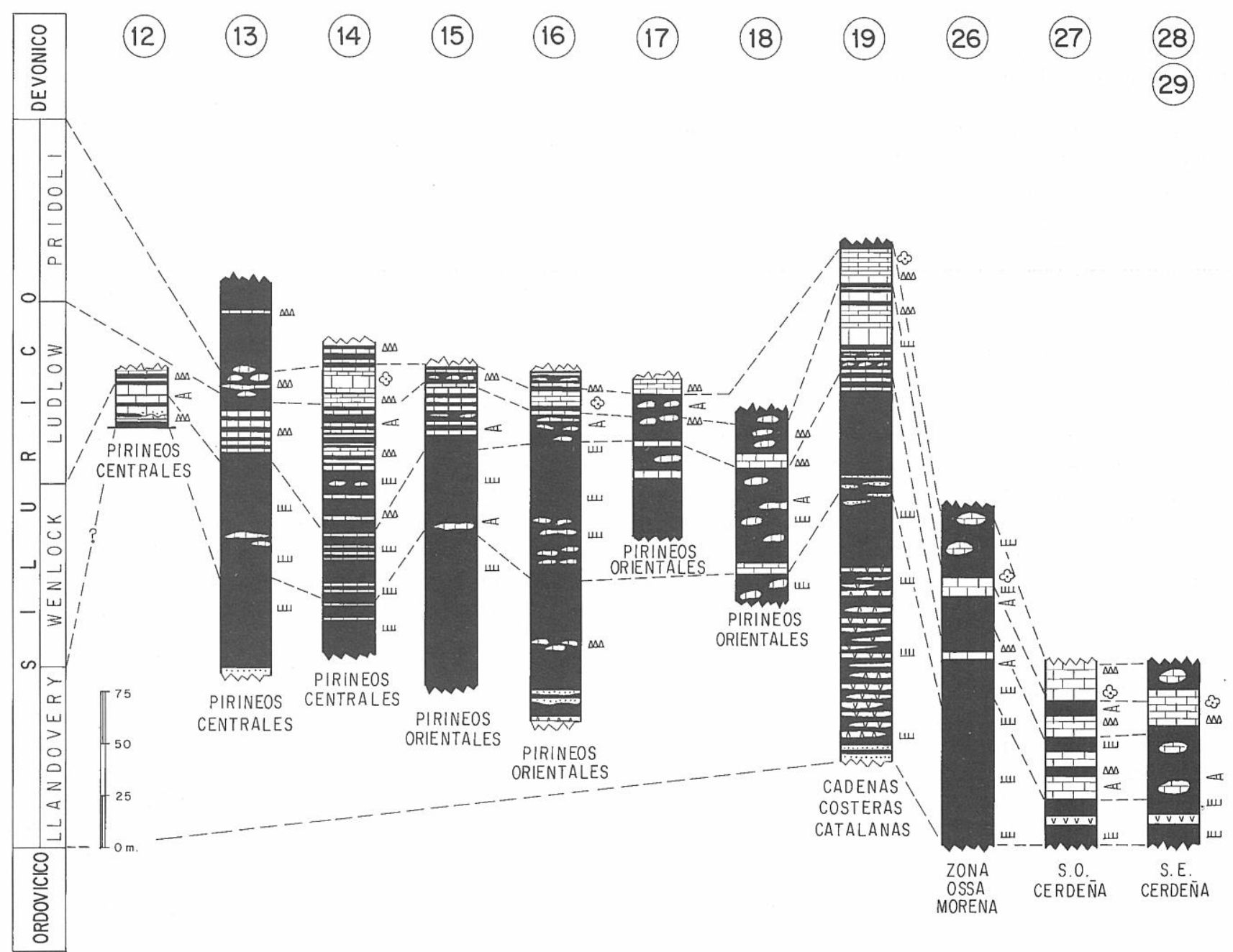

Figura 4. Sucesiones estratigráficas sintéticas del Silúrico (columnas 12-19 y 26-29) en Pirineos centrales, Pirineos orientales, Cadenas Costeras Catalanas, Zona de Ossa-Morena y Cerdeña. Los números corresponden a las localidades de la Fig. 1.

\section{Zona Cantábrica (ZC)}

En la ZC el Silúrico aflora en la Región de Pliegues y Mantos y en la Región del Pisuerga-Carrión, si bien se ha sugerido que esta última unidad provenía de la ZAOL. Los materiales silúricos de ambas regiones son comparables en líneas generales, y un análisis detallado de los mismos fue realizado por Truyols y Julivert (1983) y Aramburu et al. (1992), en quienes hemos basado nuestros datos. La mayor parte de la sucesión silúrica está formada por sedimentos siliciclásticos como pizarras, limolitas y areniscas, frecuentemente ferruginosas, así como "ironstones". hacia la parte superior. Su edad ha sido establecida fundamentalmente con graptolitos, abarcando desde las Zonas de Monograptus convolutus, Stimulograptus sedgwicki y Spirograptus turriculatus del Aeroniense medio-Telychiense basal (Llandovery medio-superior) hasta las Zonas de Cyrtograptus centrifugus y $C$. murchisoni del Sheinwoodiense inferior (Wenlock inferior), según datos de Compte (1959) y Truyols et al. (1974). La Fm. Furada/S. Pedro suprayacente, de 50 a $200 \mathrm{~m}$ de espesor, integrada por areniscas ferruginosas, con delgadas intercalaciones de pizarras y calizas arenosas, especialmente abundantes en su parte superior, representa un medio marino más somero, con fósiles bentónicos del Prído- 
li y Lochkoviense (Truyols et al., 1990). El tránsito Silúrico-Devónico es continuo y los conodontos devónicos más antiguos corresponden a la Zona de Icriodus postwoschmidti/Ozarkodina eurekaensis (García-López y Alonso-Menéndez, 1994).

La base del Silúrico ha sido reconocida solo en unos pocos afloramientos aislados de la Región de Pliegues y Mantos. El límite inferior del Silúrico se localiza en la parte superior de la Formación Castro ( Mb. Viodo), presente en su estratotipo de la costa asturiana (Figs. 1, 2; loc. 20. Tab. 4. Fig. 5; columna 20) y en el techo de dos secciones de las " Capas de Getino" (Figs. 1, 2; loc. 21. Tab. 4. Fig. 5; columna 21), de la vertiente meridional de la Cordillera Cantábrica (Sarmiento et al., 1994).

La parte superior de la Fm. Castro es un cuerpo cálcareo lenticular, Mb. Caliza de Viodo, que se depositó en un mar epicontinental somero en aparente continuidad sobre basaltos alcalinos y otros materiales volcánicos, y que lleva intercaladas tobas volcánicas. Esta sucesión es de edad Llandovery (Rhudaniense-Aeroniense), de acuerdo con el hallazgo de conodontos representivos de la "basal Lower Silurian Fauna", sucedida por las Zonas de Aspelundia petila y A. fluegeli dentro de las calizas (Sarmiento et al., op. cit.) y el hallazgo de graptolitos de la Zona de Monograptus convolutus en la base de la Fm. Formigoso suprayacente (Gutiérrez-Marco, com. pers.). Los conodontos del Llandovery de la ZC, Macizo de Mouthoumet (Loc. 8) y Pirineos (Loc. 16) son perfectamente comparables con asociaciones similares del norte de Groenlandia y Cordillera Canadiense, lo que determina la caracterización europea de las Zonas de A. petila y A fluegeli establecidas por Armstromg (1990) en Groenlandia. Esto es debido a que nuestras asociaciones provienen de calizas depositadas en una plataforma somera, emplazada en latitudes elevadas, en tanto que las otras fueron obtenidas a partir de materiales de talud que se situaban en latitudes bajas. Este hallazgo es particularmente interesante, al poner en evidencia que la temperatura fue uno de los condicionantes (tal vez el más importante) de la distribución de las poblaciones de conodontos, como ya se había advertido en otros períodos geológicos.

En gran parte de la Región de Pliegues y Mantos oriental, entre la Cuarcita de Barrios del Arenig y las Pizarras de Formigoso, se reconoce una una unidad heterolítica "Capas de Getino" (Arenig-Llandovery), formada por unos pocos metros de alternancia de areniscas, limolitas, lutitas y carbonatos (dolomías y sideritas). Los niveles ferruginosos resultan de la meteorización subaérea de rocas volcánicas básicas. El hallazgo reciente de conodontos (Figs. 1, 2; loc. 21. Tab. 4. Fig. 5 ; columna 21), en la sección de Getino ( Sarmiento et al. ,1994), apunta una edad Rhuddaniense superior o Aeroniense basal para sus tramos superiores, lo mismo que los graptolitos encontrados en otra localidad próxima ( Aramburu et al., 1992).

Salvo en la región del Cabo Peñas, donde la sucesión ordovícica es bastante completa y parece existir una sedimentación continua entre el Ordovícico y el Silúrico, en el resto de la Región de Pliegues y Mantos, las Pizarras de Formigoso se apoyan sobre las formaciones ordovícicas del Arenig o Llanvirn-Llandeilo, evidenciando la existencia de una laguna estratigráfica que comprende el Ordovícico Medio y Superior y el Llandovery inferior, o bien se apoyan sobre las "Capas de Getino", en donde la sedimentación silúrica debió de comenzar un poco antes del límite Rhuddaniense-Aeroniense, como acabamos de mencionar.

\section{Cordillera Ibérica (CI)}

El Paleozoico de la CI se interpreta como la prolongación oriental de la ZC y de la ZAOL por debajo de la cobertera terciaria y mesozoica.

El Silúrico está representado por la Fm. Bádenas, de edad Llandovery basal a Ludlow superior o Prídoli basal, constituída por 900-1400 m de pizarras negras muy finas con escasos graptolitos, pizarras arenosas y areniscas con algunos fósiles bentónicos, y niveles cuarcíticos discontinuos, más frecuentes en la mitad superior . A continuación se dispone la Fm. Luesma, de unos $215 \mathrm{~m}$ de espesor, que corresponde al Ludlow mas superior (?), Prídoli y Lochkoviense basal, y que está compuesta fundamentalmente por cuarcitas y pizarras con niveles de hierros oolíticos, conglomerados con cantos fosfatados intraformacionales, microconglomerados y calizas arcillosas con fósiles bentónicos.

Carls (1977), refiere la presencia de conodontos en las dos unidades (Figs. 1, 2; loc. 24. Tab. 4. Fig. 5; columna 24). Los

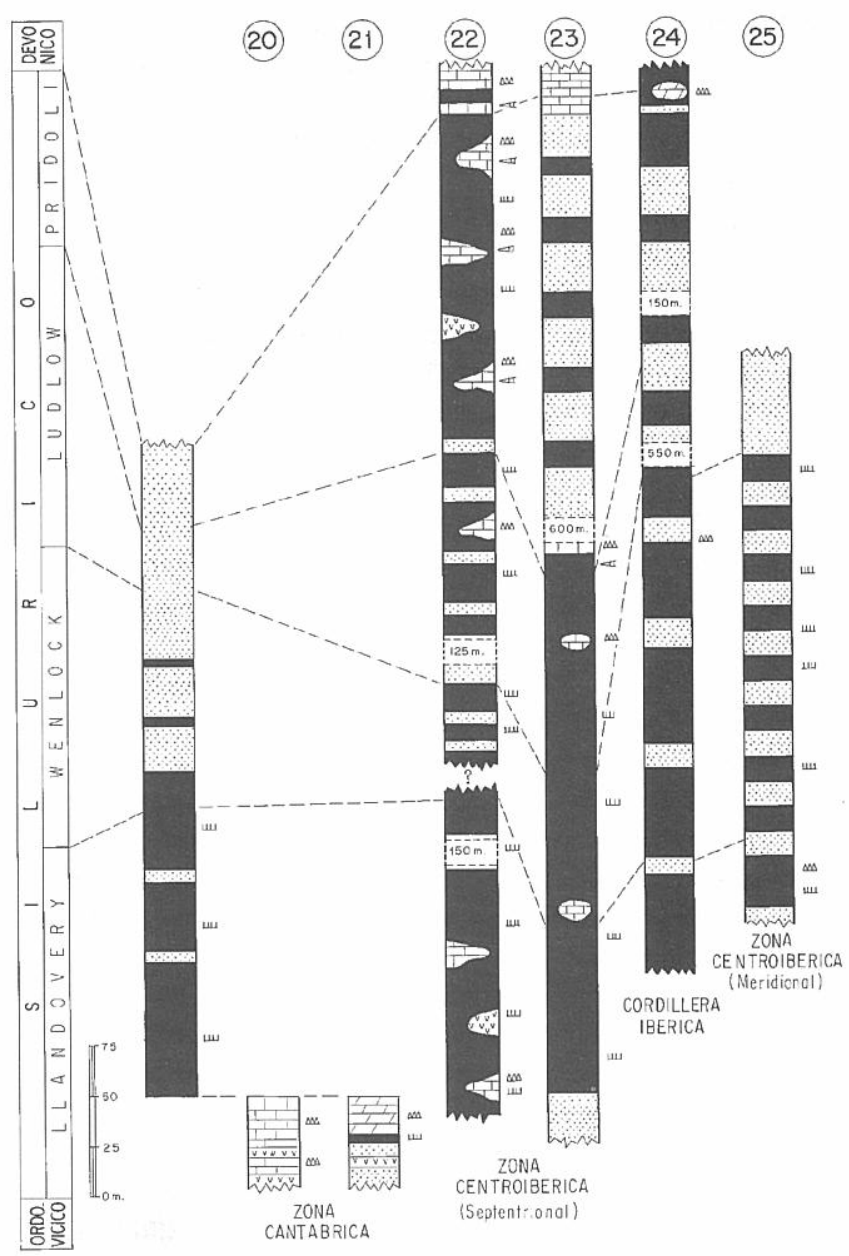

Figura 5. Sucesiones estratigráficas sintéticas del Silúrico (columnas 20-25) en la Zona Cantábrica, Zona Centroibérica y Cordillera Ibérica. Los números corresponden a las localidades de la Fig. 1. 
de la Fm. Bádenas provienen de areniscas calcáreas, y corresponden a un nivel indeterminado dentro del intervalo entre la Zona de O. sagitta y la base de la Zona de $K$. variabilis. Además, la Fm. Bádenas, en la rama castellana de la CI, contiene moldes de conodontos telychienses encontrados en ampelitas con Torquigraptus tullbergi (Gutierrez Marco, comunicación personal), cuyo estudio no ha sido todavía abordado.

Los conodontos de la Fm. Luesma fueron extraídos de niveles dolomíticos lenticulares de escasa continuidad lateral. Los taxones identificados corresponden al Devónico basal (Zona de I. w. woschmidti).

\section{Zona Centroibérica (ZCI), s.l.}

Dentro de la ZCI pueden distingirse dos dominios diferentes, cuya parte septentrional corresponde a la Subzona Galaico-Castellana (actual Dominio de los Pliegues Tumbados) y la parte meridional a la Luso Oriental-Alcudiense, Luso-Oretana o Dominio de los Pliegues Verticales. Las diferencias fundamentales entre ambas son que la tectónica tangencial, el metamorfismo y la granitización son más importantes en la primera de ellas. La mención más antigua de conodontos silúricos en la ZCI fué hecha por Redlin (1955), con restos inidentificables en las ampelitas de graptolitos. Datos mas recientes evidencian la presencia de conodontos tanto en la parte septentrional como en la meridional, proveniendo los de la parte septentrional de niveles carbonatados y los de la parte meridional de niveles siliciclásticos.

\section{ZCI (Sector septentrional)}

Los hallazgos de conodontos provienen de dos localidades, una en el "Area Trasmontana-Verín" y otra en el "Dominio del Ollo de Sapo", situadas al oeste de Zamora y en el Guadarrama oriental respectivamente.

El Sinforme de Alcañices, en la Provincia de Zamora, es una estructura compleja en la que existen dificultades para la reconstrucción estratigráfica de la sucesión Silúrica. Los conodontos, determinados por Carls, proceden de las Fms. San Vicente y Muga (Quiroga, 1980, 1982), unidades que pueden haber sido mal definidas y probablemente solaparse (Vacas y Martínez-Catalán, 1987); la columna estratigráfica y unidades donde referimos estos hallazgos deben entenderse como provisionales (Figs. 1, 2; loc. 22. Tab. 4. Fig. 5; columna 22).

La Fm. San Vicente está constituida por unos $100 \mathrm{~m}$ de pizarras con graptolitos de edad Llandovery medio (Zonas 19-21). Estas contienen algunos lentejones de calizas margosas, con conodontos tales como "Acodus cf. trigonicus" y Panderodus sp., que pueden pertenecer al Ordovícico o al Silúrico. Los graptolitos asociados, indican una edad Llandovery medio. Por encima está la Fm. Bercianos de unos $200 \mathrm{~m}$ de espesor constituida por pizarras, liditas y grauvacas con graptolitos telychienses, de las Zonas de Monograptus crispus y Monoclimacis griestonensis. Sin continuidad vertical aparece la Fm. Alba, constituída por pizarras, esquistos, liditas y cuarcitas con graptolitos de la Zona de Cyrtograptus ellesae, Sheinwoodiense terminal (Wenlock).

La Fm. Muga, suprayacente, consiste en una sucesión de liditas y calizas con intercalaciones de rocas volcanoclásticas. Las calizas con ortocerátidos, que pueden desaparecer lateralmente, contienen conodontos del Ludlow, Prídoli, Lochkoviense basal y hacia su parte alta otras formas que alcanzan el Emsiense. El paso del Ordovícico al Silúrico es díficil de observar debido a las condiciones de afloramiento, en tanto que el tránsito Silúrico/Devónico es continuo.

En el Guadarrama oriental (Dominio del Ollo de Sapo) el Silúrico está constituido, en su mayor parte, por pizarras negras arenosas con intercalaciones arcillosas, precedidas por niveles cuarcíticos asignados a la Fm. Santibáñez, probablemente del Llandovery inferior (Fernández Casals y Gutiérrez Marco, 1985). Las pizarras de la Fm. Cañamares (200-300 m de espesor) presentan en su mitad superior concrecciones calcáreas e incluyen cerca de su techo un nivel de $1 \mathrm{~m}$ de calizas arcillosas con ortocerátidos (Figs. 1, 2; loc. 23. Tab. 4. Fig. 5; columna 23). Estas últimas proporcionaron conodontos de la Zona de O. eosteinhornensis (Bultynck, 1971; Bultynck y Soers 1971), atribuidos por estos autores al Ludlow terminal, pero que se incluyen en el Prídoli de acuerdo con la escala estratigráfica adoptada en este trabajo. Entre las formas mencionadas se citan también, en posición infrayacente, morfotaxones que pueden atribuirse tanto a $K$. variabilis como a Oulodus siluricus, así como otros incluídos en $O$. e. excavata y Oulodus elegans, indicando probablemente un nivel hacia la parte superior de la Zona de $O$. crispa. Datos de graptolitos de la base de las Pizarras de Cañamares (Fernández Casals y Gutiérrez Marco, 1985), han permitido detectar las Zonas de Coronograptus cyphus, Spirograptus turriculatus, Monoclimacis griestoniensis-crenulata, Cyrtograptus centifugus o C. murchisoni, C. lundgreni y Neodiversograptus nilssoni s.l. (Ruddaniense superiorGorstiense inferior), en las pizarras negras de lo primeros 15-20 m de la sucesión. En la parte más alta de la unidad vuelven a encontrarse graptolitos (Pristiograptus sp. ex gr. dubius) y otros fósiles del Silúrico superior, en una posición estratigráfica equivalente a la de las calizas arcillosas de donde proceden los conodontos de la Zona de O. eosteinhornensis (Fernández Casals y Gutiérrez Marco, op. cit.). La Fm. Cañamares da paso a la Fm. Alcolea (840-860 m), constituida por areniscas, cuarcitas y pizarras de edad Prídoli-Lochkoviense inferior. El tránsito Silúrico/ Devónico se verifica en el tercio superior de esta unidad y no parece comportar discontinuidades.

\section{ZCI (Sector meridional)}

Dentro de la sucesión ordovícica se sitúa una importante discontinuidad estratigráfica que ha sido relacionada por distintos autores con procesos erosivos de origen glacioeustático y/o movimientos tectónicos cerca del límite Ordovícico-Silúrico. El paso del Ordovícico al Silúrico en esta región no ha podido evaluarse por la falta de datos paleontológicos (Gutiérrez-Marco et al., 1990), aunque no puede descartarse una continuidad estratigráfica local con las facies de "pelitas con fragmentos" del Hirnantiense.

Los únicos hallazgos de conodontos de este área se localizan en el sector occidental de los Montes de Toledo y corresponden a moldes externos de distintos elementos. Aquí , como en todo el área septentrional de la ZCI, los primeros sedimentos situados sobre las cuarcitas y pizarras hirnantienses (Fm. Gualija), son unas cuarcitas de gran continuidad lateral en el área (Cuarcita de Criadero), a la que se superponen 
5-25 m de pizarras negras encuadradas en la Fm. Guadarranquejo (Figs. 1, 2; loc. 25. Tab. 4. Fig. 5; columna 25). Estas contienen en su base conodontos y graptolitos del Telychiense basal (Rodríguez-Núñez et al.,1989; Sarmiento y Rodríguez-Núñez, 1991). A continuación hay una alternancia de lutitas oscuras, micáceas, con areniscas y cuarcitas (Fm. Guadarranque: 150-200 m de espesor), sucedida por las Areniscas de las Cabezuelas $(50 \mathrm{~m})$, que culminan con areniscas ferruginosas. La Formación Guadarranque es de edad Wenlock y las Areniscas de las Cabezuelas se extienden desde el límite Wenlock/Ludlow, de acuerdo con dataciones de graptolitos. Por encima no hay datos paleontológicos, pero más al sur, en el área de Herrera del Duque, sobre las ampelitas del Llandovery-Wenlock se situan areniscas con intercalaciones volcánicas alcalino-básicas y piroclásticas, con dos tramos cuarcíticos hacia el techo de la sucesión, de los cuales el inferior (Fm. Doradillo) contiene fósiles de edad Lochkoviense (Pardo y García-Alcalde, 1994 y en este volumen), por lo que se deduce que la sedimentación es continua del Silúrico al Devónico.

\section{Zona de Ossa-Morena (ZOM)}

En la Zona de Ossa Morena, al sur de la zona de cizalla de Badajoz-Córdoba, numerosos investigadores han citado pizarras negras con abundantes graptolitos (Truyols y Julivert 1983). Los estudios más detallados se han realizado en los Sinclinales del Valle y Cerrón del Hornillo (Jaeger y Robardet, 1979). La litología de la sucesión silúrica consiste, de acuerdo con Robardet y Gutiérrez Marco (1990), en: 150 $\mathrm{m}$ de pizarras negras arcillosas y síliceas, con niveles areniscosos subordinados en la parte inferior y niveles calcáreos en la parte superior. Se han identificado 21 zonas de graptoplitos que alcanzan desde la base del Llandovery (Zona de Parakidograptus acuminatus), al techo del Prídoli (Zona de Pristiograptus transgrediens). El cambio litológico mas importante tiene lugar en el Prídoli, con el desarrollo de la "Caliza de Scyphocrinites", que consiste en 10-15 m de alternancias de calizas y pizarras, que dividen la sucesión de pizarras negras en dos partes. La sedimentación es continua desde la base del Llandovery al Lochkoviense (Robardet y Gutiérrez Marco, 1990). En la "Caliza de Scyphocrinites" se han obtenido diversas asociaciones de conodontos de edad Prídoli, dentro del intervalo Pseudomonoclimacis ultimus- Pristiograptus transgrediens. Por debajo de esta caliza, las pizarras contienen lentejones calcáreos con conodontos del Ludlow (?), Cardiola y ortocerátidos (Sarmiento et al., en preparación). En otros lugares de la ZOM, la sucesión silúrica no se conoce con tanta precisión, y por ello como representativa suele darse la del Sinclinal del Valle (Figs. 1, 2; loc. 26. Tab. 4 . Fig. 4; columna 26). Esta sucesión difiere de otras del MI, donde hay una laguna entre el Ordovícico y el Silúrico, así como por su litología y carácter condensado.

\section{CERDEÑA}

El Macizo Sardo presenta la secuencia paleozoica más completa de Italia, y se subdivide en tres zonas geográficas y tectónicas: 1) la zona SO de Cerdeña o zona externa (correspondiente al Iglesiente y Sulcis) ; 2) la zona central o zona intermedia con áreas como Arburese (parte), Sarrabus, Gerrei y otras ; y 3) la zona NE o zona interna. Las condiciones sedimentarias son diferentes entre las zonas internas (con altos estructurales e hiatos por emersión), la zonas intermedias (con depósitos marinos, sobre todo terrígenos) y las zonas externas (con predominio de la sedimentación carbonatada principalmente entre el Silúrico y el Dinantiense), Vai y Cocozza (1986).

En la zona SO y central hay una secuencia bastante uniforme de las unidades del Silúrico-Devónico Inferior, con excepción de la presencia local de metabasitas alcalinas en algunos lugares de la zona central. Las secuencias del NE son poco conocidas, pero las sucesiones postordovícicas resultan similares a las de la zona externa (Vai y Cocozza, op. cit.). Así pues, el Silúrico muestra unas condiciones sedimentarias bastante homogéneas y generalizadas, representadas por las ampelitas graptolíticas y las calizas con ortocerátidos, cuyo depósito se continúa en el Devónico (Cocozza, en Bourrouilh et al., 1980). No obstante los niveles carbonatados pueden tener un desarrollo desigual, como veremos más adelante.

El Silúrico inferior tiene principalmente un magmatismo básico alcalino. En origen se trata de basaltos de tipo intraplaca continental, alcalinos a transicionales. En la parte nororiental estaban constituidos por coladas basálticas y complejos básicos estratificados de afinidades toleíticas (del tipo rift continental). En la zona externa hay raras intercalaciones de vulcanitas básicas, más desarrolladas en la zona interna.

Las principales áreas con afloramientos silúricos son Iglesiente y Sulcis al SO, y Sarrabus, Gerrei al SE. Es díficil reconocer sucesiones continuas debido a la tectónica, metamorfismo regional, intrusiones magmáticas y cambios diagenéticos, por lo que la sedimentación silúrica se ha reconstruido a partir de varios datos locales (Ferretti, 1989; Gnoli et al.,1990).

En el SO de Cerdeña, en varias localidades próximas a Fluminimaggiore y Donigala (Figs. 1, 2; loc. 27. Tab. 4 . Fig. 4; columna 27), las rocas silúricas están representadas por 20-25 m de pizarras negras arcillosas y liditas con graptolitos (Fm. Genna Muxerru, Gnoli et al., 1990). Estas han proporcionado graptolitos de las Zonas de Parakidograptus acuminatus, Cyrtograptus vesiculosus, Coronograptus cyphus?, Monograptus triangulatus, $M$. convolutus y Spirograptus turriculatus, (Gnoli et al., 1990), indicando una edad Llandovery (Rhuddaniense, Aeroniense y Telychiense basal). La base de la formación no está claramente expuesta, así que es difícil reconocer el límite $\mathrm{O} / \mathrm{S}$, aunque en el área tipo la unidad se apoya sobre pizarras del Ordovícico superior. De modo gradual, hasta llegar a hacerse predominantes aparecen intercalaciones de calizas negras, wackestone a packstone y mudstone a techo, con cefalópodos, cuyo registro abarca el tránsito Llandovery/Wenlock, Ludlow, y parte del Prídoli. En el Prídoli superior y capas del límite Silúrico-Devónico son frecuentemente características las calizas encriníticas y mícríticas con Scyphocrinites. Estos niveles carbonatados tienen 40-45 m de espesor y corresponden a la Fm. Fluminimaggiore (Gnoli et al., 1990). Las calizas alternan con pelitas no calcáreas; los fósiles más abundantes son nautiloideos ortocónicos, graptolitos, filocáridos, bivalvos, gasterópodos, y algunos braquiópodos.

Dentro de esta unidad se han reconocido conodontos de las Zonas Pterospathodus amorphognathoides, Ozarkodina 
sagitta sagitta, O. bohemica, $K$. variabilis, A. ploeckensis, $P$. siluricus, O. eosteinhornensis e I. woschmidti woschmidti. Por el contrario, las Zonas de Kockelella patula/O. sagitta rhenana, O. snajdri/Pedavis latialata y O. crispa no han podido ser identificadadas (Gnoli et al.,1990). La sedimentación carbonatada se continúa en el Lochkoviense, donde pasan a depositarse calizas nodulosas ( Fm. Mason Porcus, Gnoli et al., 1990). En el S de Cerdeña (Monte Paddentedu), se han citado conodontos del intervalo correspondiente a la parte alta de la Zona O.eosteinhornensis-Zona I. woschmidti (Prídoli-Lochkoviense), en las capas de transición entre la Fm. Fluminimaggiore y la Fm. Mason Porcus (Olivieri et al., 1980). La sedimentación del Devónico Inferior sigue siendo carbonatada.

En el SE de Cerdeña las calizas con ortocerátidos y Scyphocrinites aparecen entre las Zonas de graptolitos de $N$. nilssoni y $M$. uniformis (Ludlow-Prídoli), según datos en Jaeger (1976), Barca y Jaeger (1989). En las ampelitas silúricas infrayacentes aparecen algunos nódulos carbonatados y es posible que estos tambien se encuentren en las ampelitas lochkovienses. En Pala Manna solo han sido reconocidas unas pocas especies silúricas, algunas de amplio rango (Figs. 1, 2; Loc. 28. Tab. 4. Fig. 4; columna 28/29) . Así, la presencia de Oulodus elegans en los niveles basales de la sucesión aflorante, permiten su atribución al techo del Ludfordiense o al Prídoli. No obstante, la presencia de $P$. emarginatus en parabrechas sinsedimentarias, resedimentadas con conodontos lochkovienses, podía indicar la Zona de A. ploeckensis. En efecto, Barca et al. (1994) han señalado el hallazgo en Genna Ciuerciu and Silius $\mathrm{I}^{\circ}$, de una rica fauna de conodontos perteneciente al intervalo comprendido entre la Zona de A. ploeckensis y la Zona de O. eosteinhornensis (Figs. 1, 2; loc. 29. Tab. 4. Fig. 4; columna 28/29), si bien en este trabajo sólo se indica la presencia de taxones índice, que representan todas las zonas del intervalo mencionado.

\section{MALÁGUIDES}

El Complejo Maláguide es el complejo tectónico que se superpone a los restantes conjuntos (Alpujárride y Nevado-Filábride) que integran las Zonas Internas de la Cordillera Bética. Se trata de una unidad "alpina" que forma parte de una zona más amplia que se continúa en la parte norte de Africa (cf. Rif-Atlas Telliense). Existe cierta imprecisión en la datación de algunas de sus unidades, ya que la mayor parte de sus materiales no son fosilíferos. Diversos autores (Herbig, 1983; Martín Algarra, 1987) han atribuído al Silúrico la parte final de la Formación Morales, constituída por unos 50 $\mathrm{m}$ de lutitas pizarrosas y areniscas micáceas, aunque esta atribución no está basada en datos paleontológicos. Los conodontos silúricos hallados en el Complejo Maláguide (Figs. 1, 2; loc. 30. Tab. 5. Fig. 6; columna 30), proceden de lentejones calizos de carácter olistolítico (cuya potencia oscila entre un metro y varias decenas de metros y no tienen continuidad lateral alguna), deslizados en el seno de la Fm. Almogía, que es atribuída al Carbonífero inferior. El hallazgo de Distomodus staurognathoides, O. sagitta sagitta, K. variabilis, Polygnathoides sp. y O. remscheidensis (Kockel, 1959; Boogaard, 1965; Rodríguez-Cañero, 1993), ha permitido confir- mar, respectivamente, la presencia de horizontes del intervalo Aeroniense-base del Wenlock, del Wenlock, del Ludlow y del Lochkoviense.

\section{ÁFRICA SEPTENTRIONAL}

En el complejo montañoso del noroeste de Africa se distinguen tres grandes unidades de norte a sur: Rif-Atlas Telliense, la Zona de Mesetas y el Atlas Sahariano-Alto Atlas. Estas representan el fragmento de África afectado por las deformaciones de la Era Terciaria. El Rif, cuya prolongación hacia el norte forma la Cordillera Bética, continúa en Argelia formando el Atlas Telliense. La Zona de Mesetas está interrumpida en Marruecos por el Atlas Medio, que forma un bloque orientado SE-NO conectando el Alto-Atlas con el Rif y separando las Altas Mesetas Argelinas de la Meseta Marroquí. El Atlas-Medio divide a la Zona de Mesetas en dos partes: en el este las Altas Mesetas Argelinas, formadas por materiales terciarios, y al oeste la Meseta Marroquí en donde el Paleozoico aflora formando varios macizos.

Dentro del dominio sahariano existe un mosaico de áreas levantadas y hundidas. En las primeras la erosión ha descubierto el zócalo precámbrico, mientras que las segundas forman cuencas con gran espesor de sedimentos de cobertera. Las rocas paleozoicas afloran rodeando las zonas elevadas precámbricas en el Anti-Atlas, en el Sahara central en torno al Hoggar y en la dorsal Reguibat. Al sur del Atlas Sahariano, los terrenos formados a partir del inicio de la Era Primaria no han sufrido deformaciones importantes y los estratos son básicamente subhorizontales. En el Dominio Sahariano existe sólo una franja de rocas paleozoicas deformadas, la Cadena de Ougarta (Argelia).

Contribuciones importantes para el conocimiento del Silúrico en el NO de Africa fueron realizadas por Hollard y Willefert (in Destombes et al.,1985) y Legrand (1985) en Marruecos y Argelia respectivamente. El Silúrico aflora en todos los macizos paleozoicos de Marruecos; está generalmente separado del Ordovícico por una laguna estratigráfica de extensión variable y la sedimentación silúrica no comienza hasta el Llandovery medio o superior, incluso hasta el Wenlock superior o Ludlow. Está constituido por pizarras negras arcillosas, con abundantes graptolitos y niveles de caliza subordinados. Estos últimos se presentan inicialmente como concrecciones o nódulos y más tarde en bancos continuos.

En el Sahara Argelino, el Silúrico está representado en la Cadena de Ougarta y alrededor del macizo del Hoggar, aunque también existe en grandes extensiones por debajo de los depósitos mesozoicos. El límite inferior del Sistema no se conoce de una manera precisa, aunque en algunas localidades se aprecia una laguna estratigráfica entre el Ordovícico y el Silúrico. Es esencialmente de naturaleza arcillosa, al menos en la parte superior, y ocasionalmente presenta algunos niveles o nódulos carbonatados.

\section{GOMÁRIDES}

Los Gomárides constituyen uno de los tres grandes conjuntos estructurales integrados en las Zonas Internas de la Cordillera del Rif. La estructura de los Gomárides se halla 


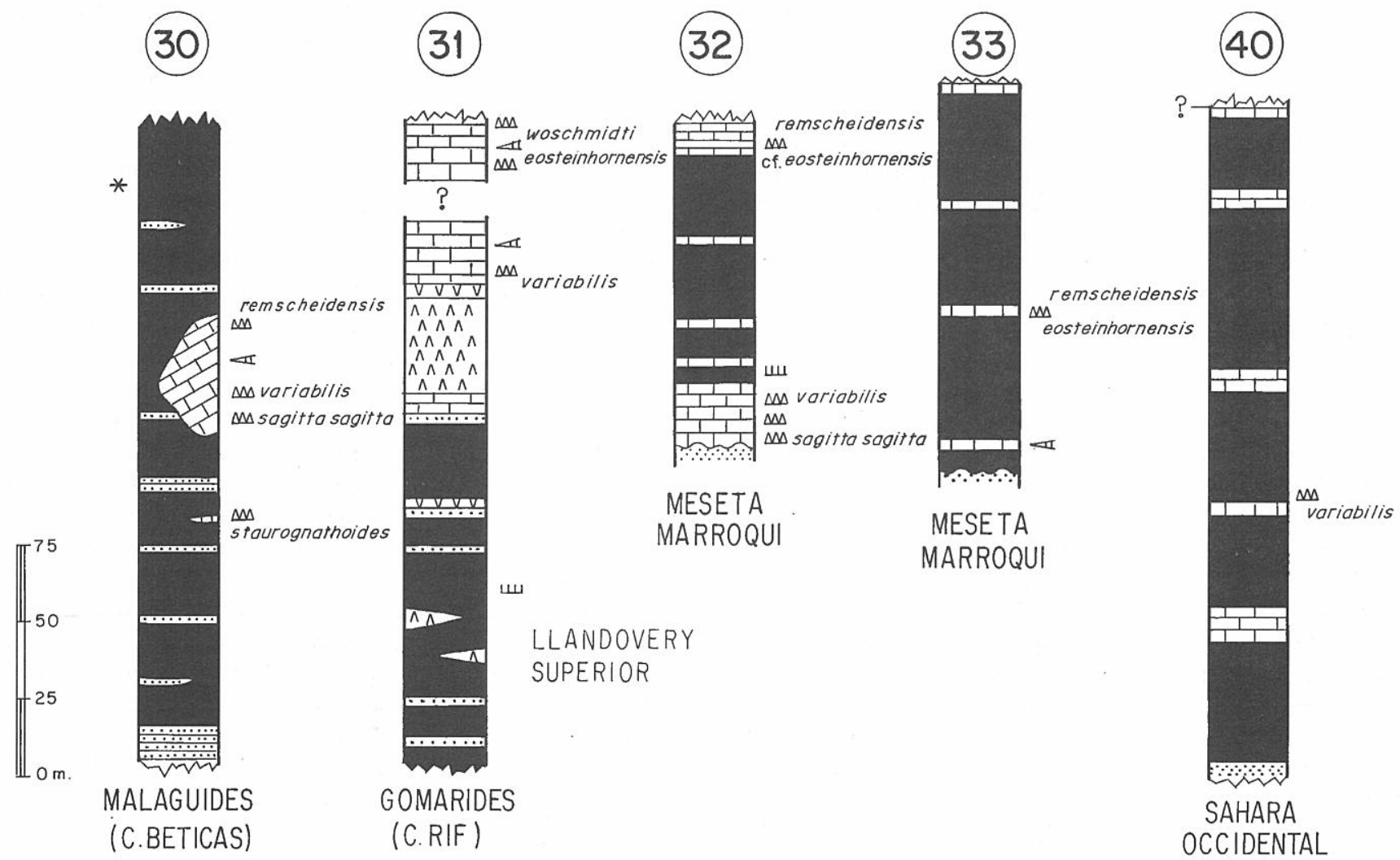

Figura 6. Sucesiones estratigráficas sintéticas del Silúrico (columnas 30-33 y 40) en Maláguides, Gomárides, Meseta Marroquí y Sahara occidental. (*) Los materiales silúricos en la Loc. 30 son olistolitos deslizados en el Carbonífero inferior. Los números corresponden a las localidades de la Fig. 1.

construída por la superposición de tres mantos de corrimiento. Fue en los esquistos del manto de Beni-Hozmar donde Agard et al. (1958) descubrieron graptolitos del Llandovery. De este mismo manto proceden los conodontos que se citan en este trabajo (Figs. 1, 2; loc. 31. Tab. 5. Fig. 6; columna 31). El Silúrico alcanza en la unidad unos 200-250 m de potencia, aunque su límite con el Ordovícico no es detectable con claridad, ni desde el punto de vista tectónico ni desde el bioestratigráfico. La parte inferior es fundamentalmente siliciclástica con rocas volcánicas y niveles silíceos, mientras que en la parte superior son más frecuentes los niveles carbonatados (Chalouan, 1987). Los datos sobre conodontos del Silúrico se reducen a un hallazgo de $K$. variabilis en un nivel de calizas con ortocerátidos en la localidad de Baïleme (Chalouan, 1987), y a la presencia de O. eosteinhornensis, $O$ remscheidensis e $I$. $w$. woschmidti procedentes de dos niveles consecutivos de calizas con ortocerátidos en la localidad de Dar Skirej (Rodríguez-Cañero et al., 1990 y datos inéditos).

\section{MESETA MARROQUí}

En el área de Rabat-Tiflet (Figs. 1, 2; Loc. 32. Tab. 5. Fig. 6; columna 32), los materiales silúrico-devónicos que forman el Macizo de Marruecos Central constituyen una sucesión marina continua desde el Wenlock al Lochkoviense, y se encuentran discordantes sobre las areniscas del Ordovícico.
El Silúrico es pizarroso con intercalaciones de calizas que son especialmente abundantes en el Wenlock superior del Oued Grou (Calizas de Mograne). El Ludlow y Prídoli son más pelíticos, aunque existen intercalaciones de calizas con ortocerátidos y Scyphocrinites. La potencia del Silúrico oscila entre unos $45 \mathrm{~m}$ en Tiflet y unos $115 \mathrm{~m}$ en el Oued Grou (Benfrika, 1994). Alberti (1969, 1977) estableció la presencia de las Zonas de graptolitos 33 y 34/35 en las Calizas de Mograne. Los conodontos determinados por Benfrika (1994) indican la presencia de las Zonas de O. sagitta, O. bohemica, parte inferior de la Zona de $K$. variabilis y la Zona de I. w. woschmidti en las Calizas de Mograne, así como la presencia de la Zona de $O$. eosteinhornensis en otras secciones de este sector.

Khemis n'Ga (Figs. 1, 2; Loc. 33. Tab. 5. Fig. 6; columna 33) es el punto más occidental con afloramientos paleozoicos de la Meseta Marroquí. La sucesión silúrico-devónica se dispone discordante sobre unas areniscas micáceas y lutitas del Ordovícico inferior. El Silúrico de esta localidad está constituido por una serie arcilloso-carbonatada de unos 120 $\mathrm{m}$ de potencia, compuesta por alternancias de niveles de calizas arcillosas, más o menos dolomíticas, y de pizarras fuertemente arenosas (Beun y Huvelin, 1992). A 10 m sobre los sedimentos del Ordovícico las calizas han proporcionado trilobites y ostrácodos del Ludlow superior-Prídoli. El conjunto de esta serie se reduce hacia el norte a unos $80 \mathrm{~m}$ de potencia; una muestra situada unos $50 \mathrm{~m}$ sobre el Ordovícico ha 
suministrado diversos conodontos del Prídoli y Devónico basal $(O$. eosteinhornenis, $O$. remscheidensis, O. excavata, O. confluens), junto con otros conodontos del Ashgill removilizados. Sobre este conjunto se disponen $400 \mathrm{~m}$ de calizas bioclásticas que contienen conodontos del Prídoli. No obstante, estos se consideran también removilizados ya que las calizas están datadas como Praguiense mediante trilobites y braquiópodos (Beun y Huvelin, 1992).

\section{ANTI-ATLAS}

El Anti-Atlas forma un abombamiento del zócalo y de los estratos de la cobertera paleozoica que lo recubren y es parte del Africa estable, es decir del continente no afectado por las deformaciones de la Era Terciaria.

Los terrenos silúrico-devónicos del Anti-Atlas se disponen formando una banda de unos $500 \mathrm{~km}$ de longitud por 30 a $50 \mathrm{~km}$ de ancho, en su flanco sur, que se extiende paralelamente al trazado del Oued Dra. Los materiales del límite Silúrico-Devónico aparecen dispuestos concordantemente, aunque no se puede descartar la existencia de alguna laguna estratigráfica. Hollard (1977) estudió tres secciones a lo largo de esta franja en las localidades de Aïn Oui n'Delouine, L'Iriqui y Taouz, que posteriormente fueron revisadas por Hollard y Willefert (in Destombes et al., 1985).

El Silúrico de Aïn Oui n'Delouine (Figs. 1, 2; Loc. 34. Tab. 5. Fig. 7; columna 34) está representado por el Grupo Taskala, con una potencia de unos $500 \mathrm{~m}$, constituído por arcillas grises con nódulos de calizas negras, ricas en sulfuros de hierro y materia orgánica; estas calizas se hacen más abundantes hacia la parte alta de la sucesión y llegan a formar niveles continuos. Esta es la única localidad de Africa septentrional en la que aparece el Llandovery basal (Hollard, 1977) indicado por la presencia de Parakidograptus acuminatus. Hollard y Willefert (in Destombes et al., 1985) describieron concrecciones carbonatadas en el tránsito Aeroniense/Telychiense o Telychiense basal y en la base del Gorstiense, así como un banco de calizas con nautiloideos ortocónicos en el Homeriense. Los conodontos, entre los que se encuentran $O$. crispa y $O$. eosteinhornensis, proceden de una barra caliza situada a $225 \mathrm{~m}$ de la base del Silúrico, y fueron asignados por Hollard (1977) al Prídoli. En asociación con estos conodontos aparece Pristiograptus e. gr. lochkovensis y unos $20 \mathrm{~m}$ debajo de la barra de caliza existe una fauna de graptolitos (Pristiograptus dubius dubius, Saetograptus tumescens, Pseudomonoclimacis haupti, Saetograptus leintwardinensis primus, Neodiversograptus sp. y Lobograptus expectatus) que indica la parte superior del Ludlow. A continuación hay $200 \mathrm{~m}$ de arcillas con intercalaciones de areniscas con Scyphocrinites y en la parte más alta aparece Monograptus e. gr. uniformis. Sobre este conjunto se dispone el Grupo del Rich (Lochkoviense), constituido por pelitas con intercalaciones de calizas y areniscas. En la base de un conjunto de cuatro barras calizas, situado a 200 m del comienzo del Grupo Rich, Hollard (1977) mencionó la presencia de Icriodus woschmidti y 100 m más arriba de I.w. woschmidti.

El Silúrico de L'Iriqui (Figs. 1, 2; Loc. 35. Tab. 5. Fig. 7; columna 35), representado también por el Grupo Taskala, está constituido fundamentalmente por arcillas con graptolitos y niveles calcáreos con ortocerátidos en el Ludlow superior- Prídoli; tambien se desarrollan algunas concreciones cálcareas en el Llandovery superior y en el Wenlock superior (Hollard y Willefert, in Destombeset al.,1985). A lo largo de la columna estratigráfica aparecen sucesivamente: Saetograptus leintwardnensis, Pseudomonoclimacis haupti, Pristiograptus e. gr. lochkovensis, Pseudomonoclimacis tomczyki, Monograptus formosus, Pseudomonoclimacis ultimus, Pristiograptus bugensis y Monograptus cf. perneri (que aparece junto a Scyphocrinites), indicando una edad Ludlow-Prídoli. En los últimos niveles se encuentra $O$. eosteinhornensis. Con el Grupo del Rich comienza el Devónico, que en esta localidad es mucho menos potente que en Aïn Oui n'Delouine, debido a su litología fundamentalmente calcárea (Hollard, 1977). En la base del Grupo coexisten O. eosteinhornesis e I. woschmidti, coexistencia que Hollard (op. cit.) explica debido a fenómenos de condensación en la sedimentación carbonatada.

El Silúrico del Anti-Atlas en el Tafilalt es mucho menos potente que en las localidades situadas más al oeste. En el corte de Taouz (Figs. 1, 2; Loc. 36. Tab. 5. Fig. 7; columna 36) aparece discordante sobre las areniscas ordovícicas y presenta una potencia de $150 \mathrm{~m}$. Está constituído por pizarras negras e intercalaciones de rocas volcánicas (doleritas). En unos horizontes calizos situados a unos $60 \mathrm{~m}$ de la base se han encontrado elementos conodontales presumiblemente del Ludlow (no incluidos en Tab. 5), además de K. variabilis y a techo de estos niveles se encuentra $M$. e. gr. lochkovensis. En el tramo final del Silúrico aparecen calizas con Scyphocrinites, ortocerátidos y conodontos tales como $O$. eosteinhornensis, O.remscheidensis y en su parte más alta $I$. woschmidti woschmidti, sobre el que se registra $M$. uniformis o $M$. praehercynicus, indicándo una edad desde el Prídoli a la base del Devónico.

\section{CADENA DE OUGARTA}

Se trata de una pequeña cadena que se orienta del noroeste al sureste de Argelia, enlazando hacia el noroeste con el Anti-Atlas marroquí. El Silúrico comienza con unos poco metros de arcillas y areniscas, con cantos ferruginosos, que contienen graptolitos de edad Llandovery medio a superior. El Wenlock está representado por $90 \mathrm{~m}$ de arcillas con graptolitos, braquiópodos y bivalvos (Legrand, 1985). El Ludlow, esencialmente arcilloso con algunas intercalaciones delgadas de calizas, (Figs. 1, 2; Loc. 37. Tab. 5. Fig. 7; columna 37) alcanza una potencia de 700-800 m (Remack-Petitot, 1960). El Prídoli, tambien arcilloso con algunos niveles carbonatados, tiene unos $250 \mathrm{~m}$ de potencia (Legrand, 1985). En esta localidad Walliser (1964) citó $K$. variabilis, determinada por Le Fèvre (1964) y P. siluricus, aunque es díficil establecer la posición exacta de los niveles de procedencia de esta fauna. Legrand (1977) menciona el hallazgo de $O$. eosteinhornensis en la segunda barra caliza del miembro medio de las Calizas del Oued Ali, situada a unos $100 \mathrm{~m}$ por debajo de unas calizas con Scyphocrinites. A unos $50 \mathrm{~m}$ sobre estas últimas se detecta la aparición de $O$. remscheidensis e $I$. woschmidti por debajo de $M$. uniformis uniformis y Warbugella rugulosa maura (Legrand, 1985). 


\section{SAHARA CENTRAL}

En el Sahara central el Paleozoico inferior aflora largamente en Argelia a lo largo del sector norte del escudo Tuareg. Remack-Petitot (1960) llevó a cabo un detallado estudio de los materiales paleozoicos en el Sahara Argelino a través del levantamiento de cortes y del estudio de muestras de sondeos. En dos de estas secciones apareció fauna de conodontos. Una síntesis del Silúrico en esta región fue realizada por Legrand (1985).

En la localidad de Foum Hassi Taïbine (Figs. 1, 2; Loc. 38. Tab. 5. Fig. 7; columna 38), situada en la cuenca de Adrar Reggane (NO del Hoggar), el Silúrico se presenta con una
Al NE del Hoggar, el Silúrico de Fort-Tarat (Figs. 1, 2; Loc. 39. Tab. 5. Fig. 7; columna 39) tiene un espesor de 440 $\mathrm{m}$ y está constituido por pizarras negras que descansan sobre unas areniscas, probablemente ordovícicas. Se han encontrado graptolitos del Llandovery medio-superior, desde $20 \mathrm{~m}$ sobre la base de la sucesión hasta $165 \mathrm{~m}$ de la misma; los mismos reaparecen en el horizonte de $365 \mathrm{~m}$. Los conodontos se han extraído de un nivel situado a $160 \mathrm{~m}$ sobre las areniscas supuestamente ordovícicas y de otros localizados unos $150 \mathrm{~m}$ más arriba, ambos conteniendo Distomodus cf. kentuckyenis del Llandovery (Remack-Petitot, 1960).

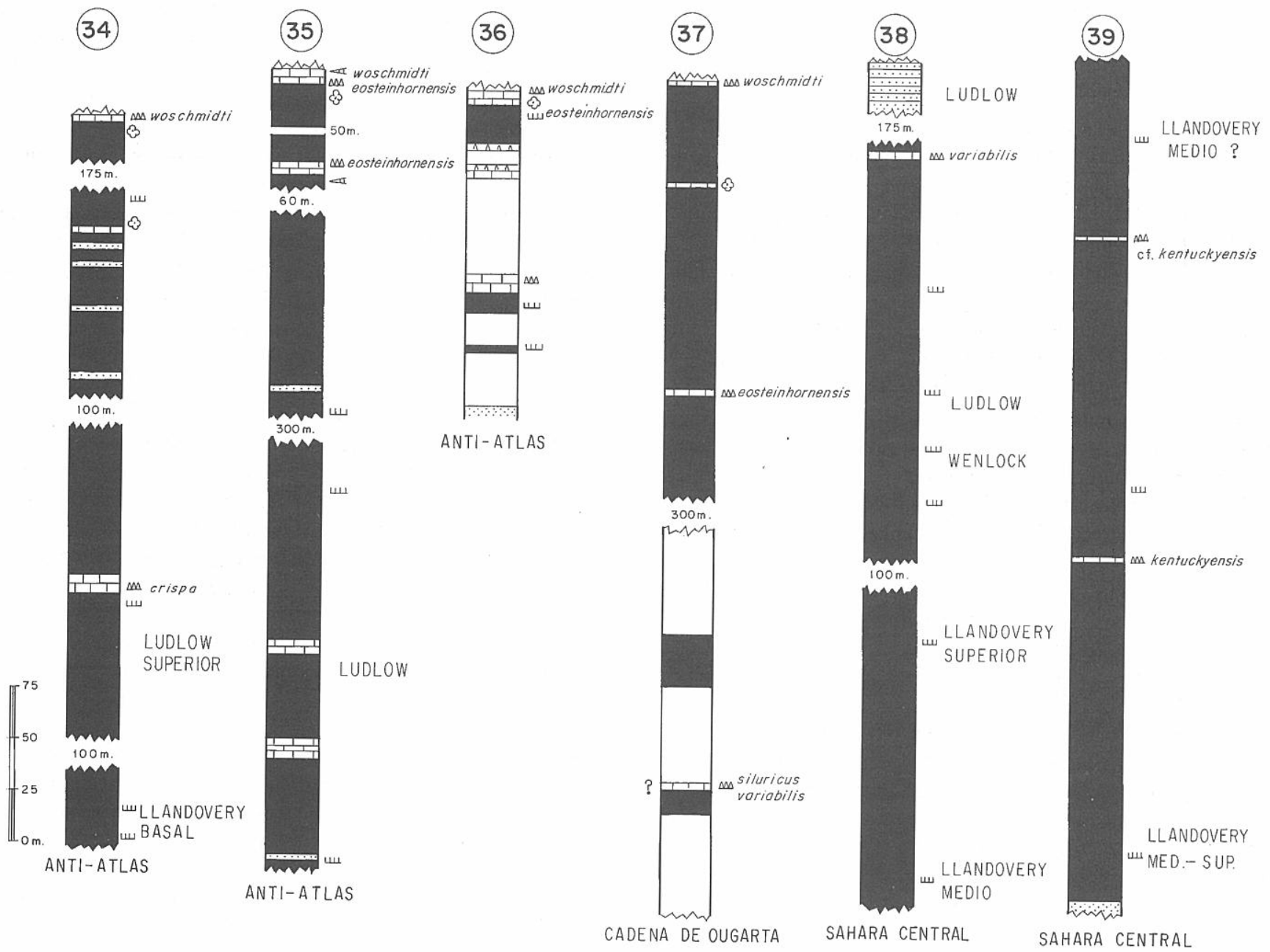

Figura 7. Sucesiones estratigráficas sintéticas del Silúrico (columnas 34-39) en Anti-Atlas, Cadena de Ougarta y Sahara central. Los números corresponden a las localidades de la Fig. 1.

potencia de $650 \mathrm{~m}$. Los primeros $300 \mathrm{~m}$ están constituidos por arcillas grises con graptolitos del Llandovery medio-superior. A continuación hay $25 \mathrm{~m}$ de arcillas del Wenlock, a las que se le superponen $125 \mathrm{~m}$ de arcillas del Ludlow inferior, caracterizadas por la presencia de Saetograptus fritschi (niveles 227 a 243). En el nivel 244 se ha encontrado K. variabilis (Remack-Petitot,1960). A todo este conjunto se superponen $200 \mathrm{~m}$ de areniscas atribuídas tentativamente al Ludlow medio-superior.

\section{CUENCA DE TINDOUF}

La cuenca de Tindouf ocupa la parte norte y central del Sahara Occidental; está limitada al norte por el cinturón plegado del Anti-Atlas y al sur por las rocas precámbricas de la dorsal Reguibat. La cuenca es asimétrica puesto que los materiales del flanco norte presentan un buzamiento más fuerte y espesores mayores que los del flanco sur. El Silúrico de este último se apoya sobre las areniscas ordovícicas y está 
constituido por pizarras negras con graptolitos y contiene niveles calcáreos muy fosilíferos, solamente conocidos en las zonas occidentales dicho flanco y más al S, en la región de Zemmour. La potencia de la secuencia silúrica es estimada por Ethington y Furnisch (1962) en más de un centenar de metros. Los conodontos de este sector (Figs. 1, 2; Loc. 40. Tab. 5. Fig. 6; columna 40) fueron extraidos de cuatro muestras de diferentes puntos, e indican un nivel indeterminado dentro del Ludlow. No obstante en dos de las muestras se encuentran ejemplares con un CAI más alto y entre ellos se cita la presencia de "Apathognatus aff. lipperti" (Frasniense) cuya presencia debe ser revisada.

\section{CONCLUSIONES}

El Sistema Silúrico en el ámbito analizado presenta dos asociaciones mayores de facies: una siliciclástica y otra siliciclástica-carbonatada. La primera está caracterizada por lutitas negras graptolíticas y en menor medida areniscas cuarcíticas y niveles de chert, que vertical y lateralmente se mantienen constantes, o bien muestran un aumento progesivo y dominante de areniscas con faunas bentónicas poco diversificadas. Comprende sucesiones de unos cientos a miles de metros de espesor, con presencia ocasional de horizontes carbonatados. La litofacies siliciclástica-carbonatada evoluciona desde ampelitas hasta la instalación gradual o episódica de la sedimentación carbonatada ("facies mediterránea", calizas con ortocerátidos, biofacies de calizas con cefalópodos,... auct.,). En la mayoría de los casos estas calizas contienen nautiloideos ortocónicos, cardiólidos y Scyphocrinites principalmente en niveles del Prídoli. Esta litofacies corresponde al desarrollo de rampas carbonatadas profundas con baja tasa de sedimentación, aunque con el incremento en el influjo clástico, aumentan las potencias de las sucesiones, al mismo tiempo que se espacian los horizontes calcáreos.

El registro de las asociaciones de conodontos en esta síntesis ha servido para evaluar fundamentalmente el inicio y la evolución de la sedimentación carbonatada. Una primera aproximación induce a agrupar los pulsos de expansión de dicha sedimentación en cuatro intervalos amplios.

Un primer episodio carbonatado se registra en el Llandovery, próximo al tránsito Rhuddaniense-Aeroniense, y ha sido identificado en Pirineos (Loc. 16), Cordillera Cantábrica (Locs. 20 y 21) y el Sahara central (Loc. 39), implicando las Zonas de A. petila y A. fluegeli en las tres primeras localidades y la Zona de Distomodus kentuckyensis en la última. Estas zonas corresponden a biofacies distintas de un intervalo temporal equivalente. Aquí se produce la transgresión sobre la rampa siliciclástica del Ordovícico superior, representada por este episodio carbonatado en áreas marginales, o bien por la instalación de facies anóxicas de ampelitas en una plataforma epicontinental de limitada profundidad.

El segundo episodio carbonatado ocurre en el Llandovery superior-Wenlock inferior. Se inicia en torno al tránsito entre las Zonas de D. staurognathoides /A. fluegeli y la Zona de $P$. celloni, y extiende hasta la Zona de $O$. sagitta. Como secciones más representativas destacan el sector meridional de la Montaña Negra (Loc. 7), suroeste de Cerdeña (Loc. 27) y la Meseta Marroquí (Loc. 32), en donde adquiere un carácter casi continuo. Discontinuo se presenta en la parte septen- trional de la Montaña Negra (Loc. 6), Macizo de Mouthoumet (Loc. 8), Pirineos (Loc. 12) y Maláguides (Loc. 30), entre otros. Se instala en rampas distales lejos del influjo clástico, quizás relacionado con la extensión y condensación de la sedimentación.

Un tercer episodio carbonatado de carácter más global se inicia próximo al tránsito Wenlock-Ludlow (en torno a la base de la Zona de $K$. variabilis o de la Zona de A. ploeckensis) y continúa desde el Ludlow superior y Prídoli (Zona de O. eosteinhornensis), bien con la instalación diacrónica de una rampa carbonatada distal poco subsidente o bien mostrando una dilución en siliciclásticos distales con relación a su situación respecto al margen. Las secuencias representativas de este episodio están en Pirineos (Locs. 10, 13, 14), Cadenas Costeras Catalanas (Loc. 19) y sureste de Cerdeña (Loc. 29); se manifiesta además en secuencias siliciclásticas como la Cadena de Ougarta (Loc. 37).

Un cuarto y último evento se localiza en el Prídoli y está bien representado, entre otras localidades, en Ardenas (Loc. 1), Pirineos (Locs. 15, 16), Macizo Hespérico (Loc. 26) y Anti-Atlas (Loc. 35) aunque tambien ha sido identificado en sucesiones siliciclásticas como Guadarrama oriental (Loc. 23).

La información contenida en esta síntesis constituye el punto de partida y la base para futuras investigaciones. Con carácter preliminar podemos realizar las siguientes consideraciones: el primer episodio carbonatado tiene un carácter local y equivale en algunos sectores al inicio de la sedimentación ampelítica, ya sea sobre una laguna estratigráfica que incluye parte del Ordovícico terminal, o como una profundización de la plataforma siliciclástica. En algunas áreas se han citado rocas volcánicas básicas y referencias a una compartimentación de las cuencas desarrollada durante el Ordovícico superior en el margen continental gondwánico. La mayor extensión de las facies de ampelitas parece anteceder o ser cercana al segundo episodio, con el amplio desarrollo de una plataforma epicontinental poco profunda y extensa, sujeta a condiciones anóxicas y con tasa de sedimentación variable. A partir del mismo se diferencian áreas con desarrollo de rampas pelágicas/hemipelágicas y áreas marginales someras siliciclásticas. El tercer y cuarto episodios corresponden a la generalización de los intervalos condensados carbonatados, que en las áreas de mayor influjo clástico están representados en determinados horizontes de profundización. Estos episodios se interpretan como intervalos de una mayor oxigenación del fondo oceánico, con una sedimentación condensada. En ellos se incluyen los episodios globales señalados por Jeppsson (1990) como cambios abióticos y aumento de la diversidad en las asociaciones de conodontos. Un modelo de ciclicidad binaria es propuesto por este autor, con cambios en la dinámica y química oceánica ligados a variaciones climáticas.

\section{AGRADECIMIENTOS}

Esta investigación ha sido subvencionada por el Proyecto PB92-1016 de la DGICYT. Los trabajos de campo realizados por Valenzuela-Ríos en los Pirineos fueron financiados por los Proyectos 061/91, 064/92 y 027/93 de la DGA, quien además recibió apoyo de la fundación A. v. Humboldt para realizar la parte final de esta colaboración. Los autores expresan su reconocimiento a los Drs. J. C. Gutiérrez-Marco del 
CSIC de Madrid, M. Robardet de la Universidad de Rennes y M. Julivert de la Universidad Autónoma de Barcelona por su inestimable su ayuda, así como por las sugerencias y correcciones hechas al manuscrito original.

\section{BIBLIOGRAFÍA}

Agard, J., Destombes, J. y Morin, Ph. 1958. Sur l'existence du Llandovery supérieur dans le massif paléozoïque interne du Rif au Nord de Tetouan (Maroc septentrional). Comptes Rendus Académie Sciences de Paris, 246, 2778-2780.

Alberti, G. K. B. 1969. Trilobiten des jüngeren Siluriums des Unterund Mitteldevons. Abhamdlungen der Senckenbergischen Naturforschenden Gesellschaft, 1-520.

Alberti, G. K. M. 1977. Rabat-Tiflet area in Morocco. In: The Silurian-Devonian Boundary. (Ed. A. Martinsson). International Union of Geological Sciences, Serie A, 5, 159-167.

Aldridge, R. J. 1988. Extinction and survival in the Conodonta. In: Extintion and Survival in the Fossil Record. .(Ed. P. Larwood). Systematics Association, Special volume, 34, 231-256. Clarendon Press, Oxford.

Aldridge, R. J. and Schönlaub, H. P. 1989. Conodonts . In: A Global Standard for the Silurian System. (Eds. C. H. Holland \& M. G. Basset). Geological Series, 9, 274-279.

Aramburu, C., Truyols, J., Arbizu, M. A., Méndez-Bedia, I., Zamarreño, I., García-Ramos, J. C., Juárez De Centi, C, y Valenzuela, M. 1992. El Paleozoico Inferior de la Zona Cantábrica. In: Paleozoico Inferior de Ibero-América.(Eds. J. C. Gutiérrez-Marco, J. Saavedra \& I. Rábano) . Universidad de Extremadura, 397-421.

Armstrong, H.A. 1990. Conodonts from the Upper OrdovicianLower Silurian carbonate platform of North Greenland. Gronlands Geologiske Undersogelse Bulletin., 159, 1-151.

Barca, S., Corradini, C., Ferretti, A., Olivieri, R and Serpagli, E. 1994. Conodont evidences from the "Okerkalt" of Southeastern Sardinia. In: IUGS Subcommission on Silurian Stratigraphy. Field Meeting Eastern + Southern Alps, Austria 1994, in mem. H. Jaeger. (Eds. H. P. Schönlaub \& L. H. Keuzer). Geologische Bundesanstalt, 30, 126.

Barca, S. and Jaeger, H. 1989. New geological and biostratigraphical data on the Silurian in SE Sardinia, close affinity with Thuringia. Bolletino della Societá Paleontologica Italiana, 108, 565-580.

Barrick, J. E. and Klapper, G. 1976. Multielement Silurian (late Llandoverian- Wenlockian) conodonts of the Clarita Formation, Arbuckle Mountains, Oklahoma, and phylogeny of Kockelella. Geologica et Palaeontologica, 10, 59-100.

Benfrika, E. M. 1994. Conodontes Siluriens et Dévoniens (WenlockGivetien) du Nord Ouest de la Meseta Marocaine: Systématique, Stratigraphie et biofacies. Tesis Doctoral, Katholieke Universiteit Leuven, 1-260. (Inédita).

Bender, P. 1967. Unterdevonische Conodonten aus den kalken von Naux (Unteres Gedinnium, Massiv von Rocroi. Geologica et Palaeontologica, 1, 183-184.

Bergström, S. M. 1990. Relations between conodont provincialism and changing palaeogegraphy during the Early Paleozoic. In: Paleozoic Paleogeography and Biogeography. (Eds. W. S. McKerrow \& C. R. Scotese). Memoir of the Geological Society of London, 12, 105-121.

Beun, N. et Huvelin, P. 1992. Le Paléozoique de Khemis-N'Ga: Discordance du Silurien supérieur sur L'Arenig (Région de
Safi, Maroc). Annales de la Société Géologique du Nord, 1, 171-177.

Boersma, K. Th. 1973. Devonian and Lower Carboniferous conodont biostratigraphy, Spanish Central Pyrénées. Leidse Geologische Mededelingen, Leiden, 49, 303-377.

Boissevain, H. 1934. Études géologique et géomorphologique d’une partie de la vallée de la Haute Sègre (Pyrénées Catalanes). Bulletin Societé Histoire Naturelle, Toulouse, 66, 33-174.

Boogaard, M. van den 1965. Two conodont faunas from the Paleozoic of the Betic of Malaga near Vélez Rubio SE Spain. Proceedings of the Koninklilke Nederlandse Akademie van Wetenschappen, 68, 33-37.

Borremans , G. et Bultynck, P. 1986. Conodóntes du calcaire de Naux-Gedinnien inferieur au Sud immédiat du Massif de Rocroi (Ardenne Francaise). Aardkundige Mededelingen, 3, 45-58.

Bourrouilh, R., Cocozza, T., Demange, M., Duran-Delga, M., Gueirards, S. Gutard, G., Julivert, M., Martínez, F. J., Massa, D., Mirouse, R. et Orsini, J. B. 1980. Essai sur l'évolution paléogéographique, structurale et métamorphique du Paléozoïque du Sud de la France et de 1'Ouest de la Méditerranée. Annales de la Societé Géologique du Nord, 99, 159-188.

Buchroithner, M. F. 1979. Conodontenstratigraphie Untersuchungen im Silur und Devon der Ost-und Zentralpyrenäen. Neus Jahrbuch für Geologie und Paläontologie Mh, 1979, 268-283.

Buchroithner, M. F., Jaeger, H. und Holzer, H.-L. 1978. Das gemeinsame Vorkommen von Graptolithen und Conodonten in einen Ludlow-Profil des Synklinoriums von Feixa-Castellás-Espahent (Zentralpyrenaen, Prov. Lerida, Spanien). Mitteilungen der Österreischischen Geologischen Gesellschaft, 68, 39-49.

Bultynck, P. 1971. Le Silurien Supérieur et le Dévonien Inférieur de la Sierra de Guadarrama. Assemblage de conodontes à Spathognathodus. Bulletin de l'Institut royal des Sciences naturelles de Belgique, 47, 1-22.

Bultynck, P. 1977. Conodontes de la Série de Liévin (Siluro-Dévonien) de l'Artois (Nord de la France). Annales de la Société Géologique du Nord, 97, 11-20.

Bultynck, P. 1982. Pridolian-Lower Gedinnian Conodont faunas from Naux (Neufchâteau Synclinorium) and from Liévin (Dinant Synclinorium). Courier Forschungsinstitut Senckenberg, 55, 135-138.

Bultynck, P. 1986. Conodontes. In: Le Groupe de Liévin. PridoliLochkovien de l'Artois (N. France). (Ed. P. R. Racheboeuf). Biostratigraphie du Paléozoïque, 3, 201-204.

Bultynck, P. et Pelhate, A. 1971. Découverte de la Zone a eostehinhornensis (Conodontes) dans le Synclinorium Médian du Massif Armoricain. In: Colloque Ordovicien-Silurien, Brest, septembre 1971. Memoires du Bureau de Recherches Géologiques et Miniérs, 73, 189-199.

Bultynck, P. et Soers, E. 1971. Le Silurien supérieur et le Dévonien Inférieur de la Sierra de Guadarrama (Espagne centrale). Bulletin de l'Institut royal des Sciences naturelles de Belgique, 47, 1-22.

Carls, P. 1977. The Silurian-Devonian boundary in the northeastern and central Spain. In: The Silurian-Devonian Boundary. International Union of Geological Sciences, Series A, 5, 143-158.

Centène, A. et Sentou, G. 1975. Graptolites et Conodontes du Silurien des massifs du Midi méditerranéen. Essai de corrélations entre les deux échelles. Thése 3éme Cycle, Montpellier, 1-191.

Chalouan, A. 1987. Les Nappes Ghomarides (Rif Septentrional, Maroc), un terrain Varisque dans la Chaine Alpine. Tesis 
Doctoral, Université Louis Pasteur, U.E.R. des Sciences de la Vie et de la Terre, Institut de Géologie, Strasbourg, 1-317.

Comte, P. 1959. Recherches sur les terrains anciens de la Cordillère Cantabrique. Memorias del Instituto Geológico y Minero de España, 60, 1-440.

Dalloni, M. 1930. Etude géologique des Pyréneés catalanes. Annales Faculté Sciences Marseille, 26, 1-373.

Dégardin, J. M. 1979. Mise en évidence de schistes d’âge Llandovérien dans les Pyrénées occidentales pae une faune à Graptolites. Intérêt stratigraphique et paléogéographique. Comptes Rendus Académie Sciences de Paris, 288, 1699-1701.

Dégardin, J. M. 1988. Le Silurien des Pyrénées. Biostratigraphie. Paléogéographie. Société Géologique du Nord, 15, 1-525.

Dégardin, J. M. et Lethiers, F. 1982. Une microfaune (Conodonta, Ostracoda) dans le Silurien terminal des Pyréneés centrales espagnoles. Revista Española de Micropaleontología, 14, 335-358.

Dégardin, J. M. et Paris, F. 1978. Présence de chitinozoaires dans les calcaires siluro-dévoniens de la Sierra Negra (Pyréneés centrales espagnoles). Geobios, 11, 769-777.

Dégardin, J. M. et Waterlot, M. 1974. Découverte de Conodontes du Dévonien inférieur dans les schistes carburés de la vallée de Bénasque (Province Huesca, Espagne). Comptes Rendus Académie Sciences de Paris, 278, 705-707.

Destombes, J., Hollard, H. and Willefert, S. 1985. Lower Palaezoic rocks of Morocco. In: Lower Palaeozoic of North-Western and West-Central Africa. (Ed. C.H. Holland), 91-336, John Wiley \& Sons.

Ethington, R. L. and Furnisch, W. M. 1962. Silurian and Devonian conodonts from the Spanish Sahara. Journal of Paleontology, 36, 1253-1290.

Faura i Sans, M. 1913. Síntesis estratigráfica de los terrenos primarios de Cataluña con una descripción de los yacimientos fosilíferos más principales. Memorias Real Sociedad Española Historia Natural, 9, 5-202.

Feist, R. und Schönlaub, H. P. 1974. Zur Silur-Devon Grenze in der Ostlichen Montagne Noire Süd-Frankreischs. Neues Jahrbuch für Geologie und Paläontologie, Abhandlungen, Stuttgart, 4, 200-219.

Fernández Casals, M. J. y Gutiérrez Marco, J. C. 1985. Aspectos estratigráficos de la Cadena Hercínica en el Sistema Central. Real Academia de Ciencias Exactas, Físicas y Naturales, Madrid, 129, 487-509.

Ferrer, E., Magrans, J. et Mañé, R. 1989. Euriptèrids (merostomats) del Devonià inferior de Bruguers (Gavà) i Santa Creu d'Olorda (Sant Feliu de Llobregat). 1 Trobada d'estudiosos de Garraf, Monografías, 19, 33-38. Diputación de Barcelona, Servicio de Parcs Naturals.

Ferretti, A. 1989. Microfacies and constituent analysis of Upper Silurian-Lowermost Devonian limestones from Southwestern Sardinia. Bolletino della Societá Paleontologica Italiana, 28, 87-100.

García-López, S. y Alonso-Menéndez, C. 1994. Conodontos del Grupo La Vid. Límites Praguiense/Emsiense y Emsiense Inferior/Emsiense Superior. Revista Española de Micropaleontología, 24, 81-97.

García-López, S., Julivert, M., Soldevila, J., Truyols-Massoni, M. y Zamarreño, I. 1990. Bioestratigrafía y facies de la sucesión carbonatada del Silúrico superior y Devónico Inferior de Santa Creu d'Olorda (Cadenas Costeras Catalanas, NE España). Acta Geológica Hispánica, 25, 141-168.
García-López, S., Rodríguez-Cañero, R., Sanz-López, J., Sarmiento, G. N. y Valenzuela-Ríos, J. I. 1994. Conodontos silúricos de Europa meridional y Africa septentrional. Comunicaciones de las X Jornadas de Paleontología, 84-88. Madrid.

Gnoli, M., Kríz, S., Leone, F., Olivieri, R., Serpagli, E. and Storch, P. 1990. Lithostratigraphic units and biostratigraphy of the Silurian and Early Devonian of Southwest Sardinia. Bolletino della Societá Paleontologica Italiana, 29, 11-23.

Greiling, L. und Puschmann, H. 1965. Die Wende Silurium/Devon am St. Creu d'Olorde bei Barcelona (Katalonien). Senckenbergiana Lethaea, 46, 453-457.

Guillot, B. L. et Le Fèvre, J. 1975. Découverte de conodontes dans le calcaire á entroques de Génis en Dordogne (série métamorphique du Bas - Limousin). Comptes Rendus de l'Académie des Sciences de Paris, 280, 1529-1530.

Gutiérrez Marco, J. C., San José, M. A. and Pieren, A. P. 1990. Zona Centro-Ibérica. Post-Cambrian Paleozoic stratigraphy. In: Pre-Mesozoic Geology of Iberia. (Eds. R. D. Dallmeyer, R. D. \& E. Martínez García). Springer-Verlag, 160-171.

Heddebaut, C. 1975. Etudes géologiques dans les Massifs paléozoïques basques (résumé de thèse). Bulletin Bureau Recherches Géologiques et Minières, 2, 5-30.

Herbig, H. G. 1983. El Carbonífero de las Cordilleras Béticas. Congreso Internacional de estratigrafía y geología del Carbonífero. In: Carbonífero y Pérmico de España. (Ed. E. Martínez Díaz). Madrid, 343-356.

Hollard, H. 1977. Le domaine de l’Anti-Atlas au Maroc. In: The Silurian-Devonian Boundary. (Ed. A. Martinsson).International Union of Geological Sciences, Serie A, 5, 168-194.

Jaeger, H. 1976. Das Silur und Unterdevon vom thüringischen Typ in Sardinien und seine regionalgeologische Bedutung. Nova Acta Leopoldina, Abhandlungen der Deutschen Akademie der Naturforcher Leopoldina, Band 45, 224, 263-299.

Jaeger H. et Robardet, M. 1979. Le Silurien et le Dévonien basal dans le nord de la province de Séville (Espagne). Géobios, 12, 687-714.

Jeppsson, L. 1990. An oceanic model for lithological and faunal changes tested on the Silurian record. Journal of the Geological Society, London, 147, 663-674.

Juch, D. et Schafer, D. 1974. L’Hercynien de Maya et de la vallée d'Arizakum dans la partie orientale du massif de Cinco-Villas (Pyrénées Occidentales de Espagne). Pirineos, 111, 41-58.

Julivert, M., Duran, H. Rickards, R. B. and Chapman, A. J. 1985. Siluro-Devonian graptolite stratigraphy of the Catalonian Coastal Ranges. Acta Geológica Hispánica, 20, 199-207.

Kockel, F. 1959. Conodontos del Paleozoico de Málaga. Notas y Comunicaciones del Instituto Geológico y Minero de España, 53, 149-164.

Le Fèvre, J. 1964. Successions d'associations d'ostracodes et de conodontes dans le Silurien, le Dévonien inférieur et l'Eifélien de quelques coupes de France et du Sahara. Mémoires du Bureau de Recherches Géologiques et Minières, 33, 48-49.

Legrand, P. 1977. Les Chaînes d'Ougarta au Sahara algérien. In: The Silurian-Devonian Boundary. (Ed. A. Martinsson).International Union of Geological Sciences, Serie A,5, 195-202.

Legrand, P. 1985. Lower Palaeozoic rocks of Algeria. In: Lower Palaeozoic of North-Western and West-Central Africa. (Ed. C.H. Holland), 91-336. John Wiley \& Sons.

Llopis Lladó, N. 1966. Sobre la estratigrafía del Silúrico de Andorra y el límite silúrico-devónico. Pirineos, 81-82, 79-86. 
Llopis Lladó, N. y Rosell Sanuy, J. 1968. Algunas aportaciones a la estratigrafía del Silúrico-Devónico de "Las Nogueras" al E de Gerri de la Sal (Lérida). Acta Geológica Hispánica, 5, 113-116.

Lys, M. et Mauvier, A. 1967. Résultats micropaléontologiques (Conodontes) dans le Silurien et le Dévonien inférieur de l'Anjou. In: Colloque sur le Dévonien inférieur et ses limites, Rennes, 1964. Mémoires du Bureau de Recherches Géologiques et Minières, 33, 391-395.

Martín Algarra, A. 1987. Evolución geológica alpina del contacto entre las Zonas Internas y las Zonas Externas de la Cordillera Bética. Tesis Doctoral, Departamento de Estratigrafía y Paleontología. Facultad de Ciencias, Universidad de Granada, 1-1.171.

Melgarejo, J. C. 1992. Estudio geológico y metalogenético del Paleozoico del sur de las Cordilleras Costeras Catalanas. Tesis de Doctorado. Memorias del Instituto Tecnológico y Geominero de España, 103, 1-605.

Olivieri, R., Mastandrea, A. e Serpagli, E. 1980. Riconoscimento di alcune zone a conodonti del Devoniano inferiori nei calcari di Monte Padenteddu nella Sardegna Meridionale. Atti Soc. Nat. Mat. di Modena, 111, 15-26.

Ovtracht, A. 1964. Gotlando-Dévonien et Dévonien inférieur du Massif de Mouthoumet (Aude). Colloque sur le Dévonien inférieur et ses limites, Rennes, 1964. Mémoires du Bureau de Recherches Géologiques et Minières, 33, 171-188.

Palau, J. and Sanz, J. 1989. The Devonian units of the Marimanya massif and their relationship with the Pyrenean Devonian facies areas. Geodinamica Acta, 3, 171-182.

Pardo Alonso, M. V. y García Alcalde, J. L. 1994. El Devónico de la Zona Centroibérica. Comunicaciones de las X Jornadas de Paleontología, 153-156. Madrid.

Pardo Alonso, M. V. y García Alcalde, J. L. En prensa. El Devónico de la Zona Centroibérica. Revista Española de Paleontología, $\mathrm{N}^{\circ}$ extraordinario X Jornadas de Paleontología.

Puschmann, H. 1968. Stratigraphische Untersuchungen in Paläozoikum des Montseny (Katalonien/Spanien). Geologische Runschau, 57, 1066-1088.

Quiroga, J. L. 1980. La sucesión silúrica en las Sierras de Aliste y Carbajales (Zamora). Cuadernos del Laboratorio Xeologico de Laxe, 1, 147-156.

Quiroga, J. L. 1982. Estudio geológico del Paleozoico del W de Zamora. Trabajos de Geología, 12, 205-226.

Racheboeuf, P. R. 1986. Les Formations du Groupe de Liévin. In: Le Groupe de Lévin. Pridoli-Lochkovien de l'Artois (N. France). (Ed. P.R. Racheboeuf). Biostratigraphie du Paléozö̈que, 3, 13-22.

Redlin, K. 1955. Stratigraphie und tectonik in der mittleren Sierra Morena in Bereich des Valle de Alcudia (Spanien). Dissertation Mathematische-Natursissenschaft Fakultaten WilhemsUniversität, 1-129.

Remack-Petitot, M. L. 1960. Contribution à l'étude des Conodontes du Sahara (Bassins de Fort-Polignac, d'Adrar Reggane et du J. Béchar). Comparaison avec les Pyrénées et la Montagne Noire. Bulletin de la Société Geologique de France, 7, 240-262.

Requadt, H. 1974. Aperçu sur la stratigraphie et les facies du Dévonien inferieur et moyen dans les Pyrénées Occidentales d'Espagne. Pirineos, 111, 109-127.

Robardet, M. and Gutiérrez Marco, J.C. 1990. Sedimentary and faunal domains in the Iberian Peninsula during lower Paleozoic times. In: Pre-Mesozoic Geology of Iberia. (Eds. R. D. Dallmeyer \& Martínez-García, E.). Part II. Cantabrian and Palentine Zones. Stratigraphy. Springer Verlag, 2, 383-395.

Rodríguez Cañero, R. 1993. Contribución al estudio de los Conodontos del Paleozoico del Complejo Maláguide (Cordillera Bética). Tesis Doctoral, Universidad de Málaga, España, 1474, (Inédita).

Rodríguez Cañero, R., Maate, A. y Martín Algarra, A. 1990. Conodontos del Paleozoico Gomáride (Rif Septentrional, Marruecos). Nota preliminar. Geogaceta, 7, 81-84.

Rodríguez Núñez, V. M., Gutiérrez Marco, J. C. y Sarmiento, G. N. 1989. Rasgos bioestratigráficos de la sucesión silúrica del Sinclinal del Guadarranque (provincias de Cáceres, Badajoz y Ciudad Real). COL-PA, Publicaciones del Departamento de Paleontología, Universidad Complutense, 42, 83-106.

Sarmiento, G. y García-López, S. 1993. Síntesis sobre las faunas de conodontos del Paleozoico Inferior de Ibero-América y de la Península Ibérica (1958-1992). Revista Española de Paleontología, 8, 191-205.

Sarmiento, G., Méndez-Bedia, I., Arbizu, M., Aramburu, C. and Truyols, J. 1994. Lower Silurian conodonts from the Cantabrian Zone, Northern Spain. Geobios, 27, 507-522.

Sarmiento, G. N. y Rodríguez Núñez, V. M. 1991. Conodontos telychienses (Silúrico inferior) del Sinclinal de Guadarranque (Zona Centroibérica, Macizo Hespérico). Revista Española de Paleontología, $n^{o}$ extraordinario, Julio 1991, 151-156.

Scotese, C. R. and McKerrow, W. S. 1990. Revised world maps and introduction. In: Paleozoic Palaeogeography and Biogeography. (Ed. W. S. McKerrow \& C. R.Scotese, C. R.). Memoir of Geological Society of London, 12, 25-41.

Schmidt, H. 1931. Das Paläozoikum der spanischen Pyrenäen. Abhandlingen der gesellschaft der Wissenschaten zu Göttingen, Math.-Phys. KI.3, Folge H.5, 8, 981-1065.

Truyols, J., Arbizu, M., García-Alcalde, J. L., García-López, S., Méndez-Bedia, I., Soto, F. and Truyols-Massoni, M. 1990. The Asturian-Leonese Domain (Cantabrian Zone). In: PreMesozoic Geology of Iberia. (Eds. R. D. Dallmeyer \& Martínez-García, E.). Part II. Cantabrian and Palentine Zones. Stratigraphy. Springer Verlag, 2, 10-19.

Truyols, J. y Julivert, M. 1983. El Silúrico en el Macizo Ibérico. In: Geología de España, 1, Libro Jubilar J.M. Ríos. (Coord. J.A. Comba). Instituto Geológico y Minero de España, Madrid, 246-265.

Truyols, J., Philippot, A. et Julivert, M. 1974. Les formations siluriennes de la Zone Cantabrique et leurs faunes. Bulletin de la Société Géologique de France, 16, 23-35.

Vacas, J. M. y Martínez-Catalán, J. R. 1987. El Sinforme de Alcañices en la transversal de Manzanal del Barco. Studia Geologica Salmanticensia, 24, 151-175.

Vai, G. B. and Cocozza, T. 1986. Tentative schematic zonation of the Hercynian chain in Italy. Bulletin de la Société Géologique de France, 8, 95-114.

Valenzuela-Ríos, J. I. 1994. Conodontos del Lochkoviense y Praguiense del Pirineo Central. Memorias del Museo de Paleontología, Universidad de Zaragoza, 5, 1-142.

Walliser, O. H. 1964. Conodonten des Silurs. Abhandlungen des Hessischen Landesamtes für Bodenforshchung zu Wiesbaden, 41, 1-106.

Manuscrito recibido: 9 de febrero, 1995 Manuscrito aceptado: 20 de octubre, 1995 


\section{ANEXO 1}

Taxones de Conodontos referidos en este trabajo, y listas de sinónimos correspondientes a sus morfotipos respectivos, de acuerdo a la reconstrucción multielemental adoptada por varios autores

Carniodus carnulus Walliser, 1964, Pa: Carniodus carnulus Walliser, 1964 (partim); Pb: Carniodus? carinthiacus Walliser, 1964; M: Carniodus carnicus Walliser, 1964; Sa: Roundya latialata Walliser, 1964, Roundya brevialata (Walliser, 1964), Exochognathus latialatus (Walliser, 1964); Sb: Carniodus carnulus Walliser, 1964 (partim); Sc: Carniodus carnus Walliser, 1964.

Distomodus kentuckyensis Branson \& Branson, 1947, Pa: Icriodina irregularis Branson \& Branson, 1947; Pb: Drepanodus simplex Branson \& Branson, 1947; Drepanodus? arrectus Rexroad, 1967; M: Distomodus kentuckyensis Branson \& Branson, 1947; Sa: Trichonodella brassfieldensis Branson \& Branson, 1947; Exochognathus brassfieldensis (Branson \& Branson, 1947); Sb: Roundya caudata Walliser, 1964; Exochognathus caudatus (Walliser, 1964); Exochognathus detortus (Walliser, 1964); Sc: Distomodus egregius (Walliser, 1964), Ligonodina? extrorsa Rexroad, 1967; Distomodus extrorsus (Rexroad, 1967).

Distomodus staurognathoides (Walliser, 1964); Pa: Hadrognathus staurognathoides Walliser, 1964; Pb: Trichonodella expansa Nicoll \& Rexroad, 1969; Exochognathus expansus (Nicoll \& Rexroad, 1969); Ambalodus carnicus Schönlaub, 1971; M: Distomodus kentuckyensis Branson \& Branson, 1947; Sa: Trichonodella brassfieldensis Branson \& Branson, 1947; Exochognathus brassfieldensis (Branson \& Branson, 1947); Sb: Roundya caudata Walliser, 1964; Exochognathus caudatus (Walliser, 1964); Exochognathus detortus (Walliser, 1964); Sc: Ligonodina egregia Walliser, 1964; Distomodus egregia (Walliser, 1964).

Kockelella absidata Barrick \& Klapper, 1976; Pa: Spathognathodus cf. primus (Branson \& Mehl, 1933); $\mathrm{Pb}$ : Ozarkodina fundamentata (Walliser, 1964).

Kockelella patula Walliser, 1964; Pa: Kockelella patula Walliser, 1964; Pb: Ozarkodina ziegleri aequalis Walliser, 1964; M:Neoprioniodus multiformis Walliser, 1964.

Kockelella ranuliformis (Walliser, 1964); Pa: Spathognathodus ranuliformis Walliser, 1964.

Kockelella variabilis Walliser, 1957; Pa: Kockelella variabilis Walliser, 1957; Pb: Ozarkodina ziegleri Walliser, 1957; M: Prioniodus excavatus Branson \& Mehl, 1933, Neoprioniodus multiformis Walliser, 1964; Prioniodina excavata (Branson \& Mehl, 1933), Prioniodina armata (Hinde, 1879); Sa: Trichonodella inconstans Walliser, 1957; Sb: Lonchodina greilingi Walliser, 1957; Sc: Ligonodina silurica Branson \& Mehl, 1933.

Oulodus elegans detorta (Walliser, 1964); $\mathrm{Pb}$ : Lonchodina detorta Walliser, 1964; Sc: Ligonodina elegans Walliser, 1964; Delotaxis elegans (Walliser, 1964); Ligonodina elegans detorta Walliser, 1964.

Oulodus elegans elegans (Walliser, 1964); $\mathrm{Pb}$ : Lonchodina detorta Walliser, 1964; Sc: Ligonodina elegans Walliser, 1964; Delotaxis elegans (Walliser, 1964); Ligonodina elegans elegans (Walliser, 1964).

Ozarkodina bohemica (Walliser, 1964); Pa: Spathognathodus sagitta bohemicus Walliser, 1964; Pb: Ozarkodina edithae Walliser, 1964.

Ozarkodina confluens (Branson \& Mehl, 1933); Pa: Spathognathodus primus Branson \& Mehl, 1933; $\mathrm{Pb}$ : Ozarkodina typica Branson \& Mehl, 1933; M: Prioniodus bicurvatus Branson \& Mehl, 1933; Sa: Trichognathus symmetrica Branson \& Mehl,
1933; Sb: Plectospathodus flexuosus Branson \& Mehl, 1933; Sc: Hindeodella confluens Branson \& Mehl, 1933.

Ozarkodina crispa (Walliser, 1964); Pa: Spathognathodus crispus Walliser, 1964.

Ozarkodina excavata excavata (Branson \& Mehl, 1933); Pa: Ozarkodina simplex Branson \& Mehl, 1933); Prioniodella inclinata Rhodes, 1953; Spathognathodus inclinatus (Rhodes, 1953); Spathognathodus dubius Ethington \& Furnish, 1962; Pb: Ozarkodina media Walliser, 1964; M: Prioniodus excavatus Branson \& Mehl, 1933; Sa: Trichognathus excavatus Branson \& Mehl, 1933; Trichonodella aboroflexa Rhodes, 1953; Trichonodella excavata Branson \& Mehl, 1966; Sb: Plectospathodus extensus Rhodes, 1953; Sc: Hindeodella equidentata Rhodes, 1953.

Ozarkodina eosteinhornensis (Walliser, 1964); Pa: Spathognathodus steinhornensis eosteinhornensis Walliser, 1964; Pb: Ozarkodina typica denckmanni Ziegler, 1964; M: Neoprioniodus bicurvatus Branson \& Mehl, 1933; Sa: Trichonodella symmetrica (Branson \& Mehl, 1933); Sb: Plectospathodus alternatus Walliser, 1964; Sc: Hindeodella priscilla Stauffer, 1938.

Ozarkodina remscheidensis (Ziegler, 1960); Pa: Spathognathodus remscheidensis Ziegler, 1969; Spathognathodus cf. frankenwaldensis Bischoff \& Sannemann, 1958; Spathognathodus steinhornensis remscheidensis Ziegler, 1976; Pb: Ozarkodina denckmanni Ziegler, 1956 Ozarkodina typica denckmanni Ziegler, 1964; M: Prioniodus bicurvatus Branson \& Mehl, 1933; Neoprioniodus bicurvatus (Branson \& Mehl, 1933); Prionodina bicurvata pronoides Walliser, 1964; Sa: Dichognathus symmetrica Branson \& Mehl, 1933; Trichonodella symmetrica (Branson \& Mehl, 1933); Sb: Plectospathodus alternatus Walliser, 1964; Sc: Hindeodella priscilla Stauffer, 1938.

Ozarkodina sagitta rhenana (Walliser, 1964); Pa: Spathognathodus sagitta rhenanus Walliser, 1964; Pb: Ozarkodina edithae Walliser, 1964; M: Neoprioniodus bicurvatoides Walliser, 1964.

Ozarkodina sagitta sagitta (Walliser, 1964); Pa: Spathognathodus sagitta sagitta Walliser, 1964; Pb: Ozarkodina edithae Walliser, 1964; M: Neoprioniodus bicurvatoides Walliser, 1964.

Ozarkodina snajdri (Walliser, 1964); Pa: Spathognathodus snajdri Walliser, 1964.

Pedavis latialata (Walliser, 1964); I: Icriodus latialatus Walliser, 1964.

Pterospathodus amorphognathoides Walliser, 1964; Pa: Pterospathodus amorphognathoides Walliser, 1964; Pb: Ozarkodina gaertneri Walliser, 1964; Ozarkodina neogaertneri Nicoll \& Rexroad, 1969; M: Neoprioniodus triangularis triangularis Walliser, 1964; Distomodus triangularis triangularis (Walliser, 1964); S: Neoprioniodus costatus costatus Walliser, 1964.

Pterospathodus celloni (Walliser, 1964); Pa: Spathognathodus celloni Walliser, 1964, Llandoverignathus celloni (Walliser, 1964); Roundya brevialata Walliser, 1964; Pb: Ozarkodina adiutricis Walliser, 1964; M: Neoprioniodus triangularis tenuirrameus Walliser, 1964; S: Neoprioniodus costatus paucidentatus Walliser, 1964.

Pterospathodus pennatus Walliser, 1964; Pa: Spathognathodus pennatus pennatus Walliser, 1964; Llandoverygnathus pennatus (Walliser, 1964). 


\section{ANEXO 2}

Taxones de Conodontos silúricos y del límite Silúrico-Devónico identificados en el ámbito de este trabajo.

"Acodus trigonicus" (Schopf, 1966).

Ancoradella ploeckensis Walliser, 1964.

Aspelundia fluegeli (Walliser, 1964).

Aspelundia petila (Nicoll \& Rexroad, 1969).

Aulacognathus kuehni Mostler, 1967.

Belodella devonica (Stauffer, 1940).

Belodella resima (Philip, 1965).

Belodella silurica Barrick, 1977.

Belodella triangularis (Stauffer, 1940).

Carniodus carnulus Walliser, 1964.

Carniodus sp.

Dapsilodus obliquicostatus (Branson \& Mehl, 1933).

Decoriconus fragilis (Branson \& Mehl, 1933).

Distomodus cf. kentuckyensis Branson \& Branson, 1947.

Distomodus staurognathoides (Walliser, 1964).

Distomodus sp.

Icriodus woschmidti woschmidti Ziegler, 1960.

Kockelella absidata Barrick \& Klapper, 1976.

Kockelella patula Walliser, 1964.

Kockelella ranuliformis (Walliser, 1964).

Kockelella stauros Barrick \& Klapper, 1976.

Kockelella variabilis Walliser, 1957.

Kockelella sp.

Oulodus elegans elegans (Walliser, 1964).

Oulodus elegans detorta (Walliser, 1964).

Oulodus elegans ssp. indet.

Oulodus siluricus (Branson \& Mehl, 1933).

Oulodus sp.

Ozarkodina bohemica (Walliser, 1964).

Ozarkodina confluens (Branson \& Mehl, 1933).

Ozarkodina crassa Walliser, 1964.

Ozarkodina crispa (Walliser, 1964).

Ozarkodina eladioi Valenzuela Ríos, 1994.
Ozarkodina eosteinhornensis (Walliser, 1964.

Ozarkodina excavata excavata (Branson \& Mehl, 1933).

Ozarkodina excavata emanciata (Walliser, 1964).

Ozarkodina excavata inflata (Walliser, 1964).

Ozarkodina excavata posthamata (Walliser, 1964).

Ozarkodina remscheidensis remscheidensis (Ziegler, 1960).

Ozarkodina remscheidensis "40" Gong \& Carls, en prensa.

Ozarkodina remscheidensis ssp. indet.

Ozarkodina sagitta sagitta (Walliser, 1964).

Ozarkodina sagitta rhenana (Walliser, 1964).

Ozarkodina sagitta ssp. indet.

Ozarkodina snajdri (Walliser, 1964).

Panderodus feulneri (Glenister, 1957).

Panderodus langkawiensis (Igo \& Koike, 1967).

Panderodus panderi (Stauffer, 1940).

Panderodus recurvatus (Rhodes, 1953).

Panderodus unicostatus (Branson \& Mehl, 1933).

Panderodus sp.

Pedavis latialata (Walliser, 1964).

Pelekysgnathus index Klapper \& Murphy, 1975.

Polygnathoides emarginatus (Branson \& Mehl, 1933).

Polygnathoides siluricus Branson \& Mehl, 1933.

Polygnathoides sp.

Pseudooneotodus beckmanni (Bischoff \& Sannemann, 1958).

Pseudooneotodus bicornis Drygant, 1974.

Pseudooneotodus tricornis Drygant, 1974.

Pterospathodus amorphognathoides Walliser, 1964.

Pterospathodus celloni (Walliser, 1964).

Pterospathodus sp.

Walliserodus blackstonensis McCracken, 1991.

Walliserodus curvatus (Branson \& Branson, 1947).

Walliserodus santiclairi Cooper, 1976. 